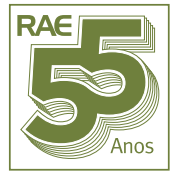

ESPECIAL RAE

Artigo convidado

DOI: http://dx.doi.org/10.1590/So034-759020170407

\title{
EXPLORAÇÃO DO ACERVO DA RAE-REVISTA DE ADMINISTRAÇÃO DE EMPRESAS (DE 1961 A 2016) À LUZ DA BIBLIOMETRIA, TEXT MINING, REDE SOCIAL E GEOANÁLISE
}

\author{
Exploring the archive of RAE-Revista de Administração de Empresas (1961 - 2016) in the \\ light of bibliometrics, text mining, social network and geoanalysis \\ Exploración del acervo de la RAE-Revista de Administração de Empresas (1961 - 2016) a \\ la luz de la bibliometría, text mining, rede social y geoanálisis
}

\section{RESUMO}

Este artigo analisou mais de cinco décadas do acervo da Revista de Administração de Empresas (RAE), entre 1961 e 2016, pelo acesso aos documentos disponibilizados via internet no repositório eletrônico de periódicos e revistas da Biblioteca Digital da Fundação Getulio Vargas - Escola de Administração de Empresas de São Paulo, o qual segue o protocolo aberto Open Archives Initiative - Protocol for Metadata Harvesting (OAI-PMH) de interoperabilidade entre repositórios digitais. Um total de 2.381 documentos publicados no periódico (1.422 artigos, 217 editoriais, 62 pensatas e 680 resenhas) foi coletado de modo automatizado e posteriormente analisado com a utilização de técnicas de bibliometria, text mining, rede social e geoanálise. Este estudo permite compreender a trajetória da existência do periódico RAE em seus 22 diferentes períodos de gestão, o incremento da autoria nas publicações do periódico em 14 intervalos de tempo, os termos e palavras-chave com mais frequência e importância nos documentos publicados, bem como a formação das redes de coautoria dos pesquisadores que contribuíram para o desenvolvimento da ciência da Administração no País.

PALAVRAS-CHAVE | Periódico científico RAE, análise bibliométrica, text mining, análise de redes sociais, geoanálise.

\begin{abstract}
This article examined more than five decades of the Revista de Administração de Empresas (Journal of Business Administration [RAE]), between 1961 and 2016, through accessing documents made available on the internet in the electronic repository of periodicals and magazines of the Biblioteca Digital da Fundação Getulio Vargas-Escola de Administração de Empresas de São Paulo (Digital Library of the Getulio Vargas Foundation-School of Business Administration of São Paulo), which follows the Open Archives Initiative-Protocol for Metadata Harvesting $(O A /-P M H)$ of interoperability between digital repositories. A total of 2,381 documents published in the journal (1,422 articles, 217 editorials, 62 opinion articles, and 680 reviews) were collected through an automated process and later analyzed using techniques such as bibliometrics, text mining, social networking, and geo-analysis. This study enables understanding of the path that the RAE journal has followed throughout its existence including 22 different management periods, the increase of authorship within its publications during 14 time intervals, the most frequent and important terms and keywords appearing in its published documents, and the formation of co-authoring networks of researchers who contribute to the development of the Administration science in the Country.

KEYWORDS / Scientific journal RAE, bibliometric analysis, text mining, social network analysis, geo-analysis
\end{abstract}

\section{RESUMEN}

Este artículo analizó más de cinco décadas del acervo de la Revista de Administração de Empresas (RAE) -entre 1961 y 2016-mediante el acceso a documentos disponibles en internet, en el repositorio electrónico de periódicos y revistas de la Biblioteca Digital de la Fundação Getulio Vargas - Escuela de Administración de Empresas de São Paulo, que sigue el protocolo abierto Open Archives Initiative - Protocol for Metadata Harvesting (OAI$-P M H)$ de interoperabilidad entre repositorios digitales. En total, se recolectaron de forma automatizada 2.381 documentos publicados en el periódico (1.422 artículos, 217 editoriales, 62 pensatas y 680 reseñas) y posteriormente se analizaron utilizando técnicas de bibliometría, text mining, redes sociales y geoanálisis. Este estudio permite comprender la trayectoria del periódico RAE en sus 22 diferentes períodos de gestión, el incremento de la autoría en las publicaciones del periódico en 14 intervalos de tiempo, los términos y palabras clave más frecuentes e importantes en los documentos publicados, así como la formación de las redes de coautoría de los investigadores que contribuyeron al desarrollo de la ciencia de la Administración en el País.

PALABRAS CLAVE / Periódico científico RAE, análisis bibliométrico, text mining, análisis de redes sociales, geoanálisis. 


\section{INTRODUÇÃO}

Diversos periódicos científicos brasileiros da área da Administração já foram objeto de estudos que exploraram o mapeamento do acervo de suas produções científicas, entre eles, a RAE-eletrônica (Francisco, 2011), a Brazilian Administration Review (BAR) (Ribeiro \& Costa, 2013), a Revista de Administração Pública (RAP) (Ribeiro, 2014a), a Revista Eletrônica de Negócios Internacionais (Internext) (Ribeiro, 2014b), a Revista Brasileira de Inovação (RBI) (Ribeiro \& Corrêa, 2014), a Revista de Administração Contemporânea (RAC) (Ribeiro, 2015) e a Revista de Administração da USP (RAUSP) (Ribeiro, Corrêa, Costa, \& Fischmann, 2016), com a utilização de variadas técnicas de análise.

A literatura acadêmica também relata estudos que comemoram a longevidade de periódicos estrangeiros, entre eles os 33 anos do Journal of Econometrics (Amemiya, 2009), os 40 anos do Journal of Management (Fleet \& Bedeian, 2016) e os 50 anos do periódico Management Science, na visão da pesquisa em sistemas de informação (Banker \& Kauffman, 2004).

Em estudo que avaliou as 10 revistas científicas brasileiras de maior acesso na biblioteca eletrônica do Scientific Electronic Library Online (SciELO) em oito diferentes áreas do conhecimento (Medeiros, 2016) e utilizou dados da ferramenta SciELO Analytics (SciELO, 2017) no período de setembro de 2015 a agosto de 2016, foi atribuída à $R A E$ a primeira colocação entre os periódicos pertencentes à área de Ciências Sociais Aplicadas, e também a sexta posição entre as revistas mais acessadas no ranking geral dessa plataforma, com um total de 3.011 .534 acessos no período mensurado (Medeiros, 2016; RAE, 2016).

A RAE, publicada pela Escola de Administração de Empresas de São Paulo, da Fundação Getulio Vargas (FGV EAESP), foi lançada em maio de 1961 (FGV, 1961), e sua publicação ininterrupta atingiu o total de 56 volumes completos no final do ano de 2016.

Como um periódico consolidado no meio acadêmicocientífico do País, com foco generalista na área de Administração e dirigido para professores, pesquisadores e estudantes, seu acervo digital tem acesso aberto sem restrições para toda a comunidade.

A RAE está classificada na Plataforma Sucupira-Qualis 2013-2016 (Coordenação de Aperfeiçoamento de Pessoal de Nível Superior [Capes], 2017) como um periódico A2, no Scimago Journal \& Country Rank 2016 (SJR, 2017) com o índice SJR de 0,155 e no Journal Citation Reports-Thomson Reuters 2016 (JCR, 2017) com o Fator de Impacto de 0,408. Das revistas científicas brasileiras listadas na coleção do Social Sciences Citation Index (SSCl), a $R A E$ ocupa a oitava posição entre os periódicos das demais áreas, mas é a primeira da área de conhecimento da Administração, conforme ranking divulgado em junho de 2017. Consideramos que, nesta edição especial de aniversário, justifica-se destacar os principais períodos da revista e suas características. A próxima seção apresenta um breve histórico do periódico; em seguida, é descrito o procedimento de coleta e análise dos dados, e, na sequência, são identificados e discutidos os resultados.

\section{A RAE-REVISTA DE ADMINISTRAÇÃO DE EMPRESAS}

Nesta jornada de mais de cinco décadas de vida, a gestão de conteúdo editorial da $R A E$ teve a direção conduzida por diretores, redatores ou editores-chefes, em 22 diferentes períodos, como informado no Quadro 1.

Durante os três primeiros períodos de administração do periódico, de maio-agosto de 1961 até abril-junho de 1968, os próprios diretores acumulavam os cargos de redatores-chefes do periódico. A partir do volume 8 , número 28 , de julho-setembro de 1968 , os diretores passaram a contar com o auxílio de redatoreschefes, os quais permaneceram atuantes na gestão do conteúdo do periódico até o volume 29, número 4, do ano de 1989.

Nos artigos publicados no periódico do ano de 1989 (volume 29) em diante, além dos resumos na língua portuguesa, foram também inseridos resumos na língua inglesa.

A partir do ano de 1990, na gestão da professora Gisela Taschner Goldenstein, deixou de existir o cargo de redator-chefe, e o diretor da RAE passou a também acumular o cargo de editorchefe do periódico, permanecendo dessa forma até os dias atuais. Em abril-junho de 1991 (volume 31, número 2), a própria professora também relata em editorial a comemoração dos 30 anos da RAE (Goldenstein, 1991).

Entre todos os diretores da RAE em seus 22 períodos de gestão, dois deles repetiram sua passagem pela revista: 0 professor Carlos Osmar Bertero, com a primeira participação no período 3 (de janeiro-março de 1967 a abril-junho de 1968) e a segunda participação no período 18 (de abril-junho de 2005 a outubro-dezembro de 2007), e o professor Sérgio Micelli Pessoa de Barros, que participou do período 9 (de abril-junho de 1980 a janeiro-março de 1982) e do período 11 (de janeiro-março de 1984 a julho-setembro de 1985). Visto pelo total de tempo em que ocupou o cargo de gestor da RAE, o professor Eduardo H. Diniz foi o editor-chefe que mais tempo permaneceu no periódico (Diniz, 2016), de julho de 2009 a janeiro de 2016 - aproximadamente sete anos, seguido em longevidade pelo professor Roberto Venosa, com cinco anos de permanência na $R A E$ - de janeiro de 1996 a janeiro de 2001. 
Quadro 1. Períodos de atuação de cada diretor, redator ou editor-chefe responsável pela RAE de 1961 a 2016 organizados por ordem cronológica crescente das edições (volumes e números) e pelos meses das publicações, conforme participações na assinatura do editorial e/ou no expediente do periódico

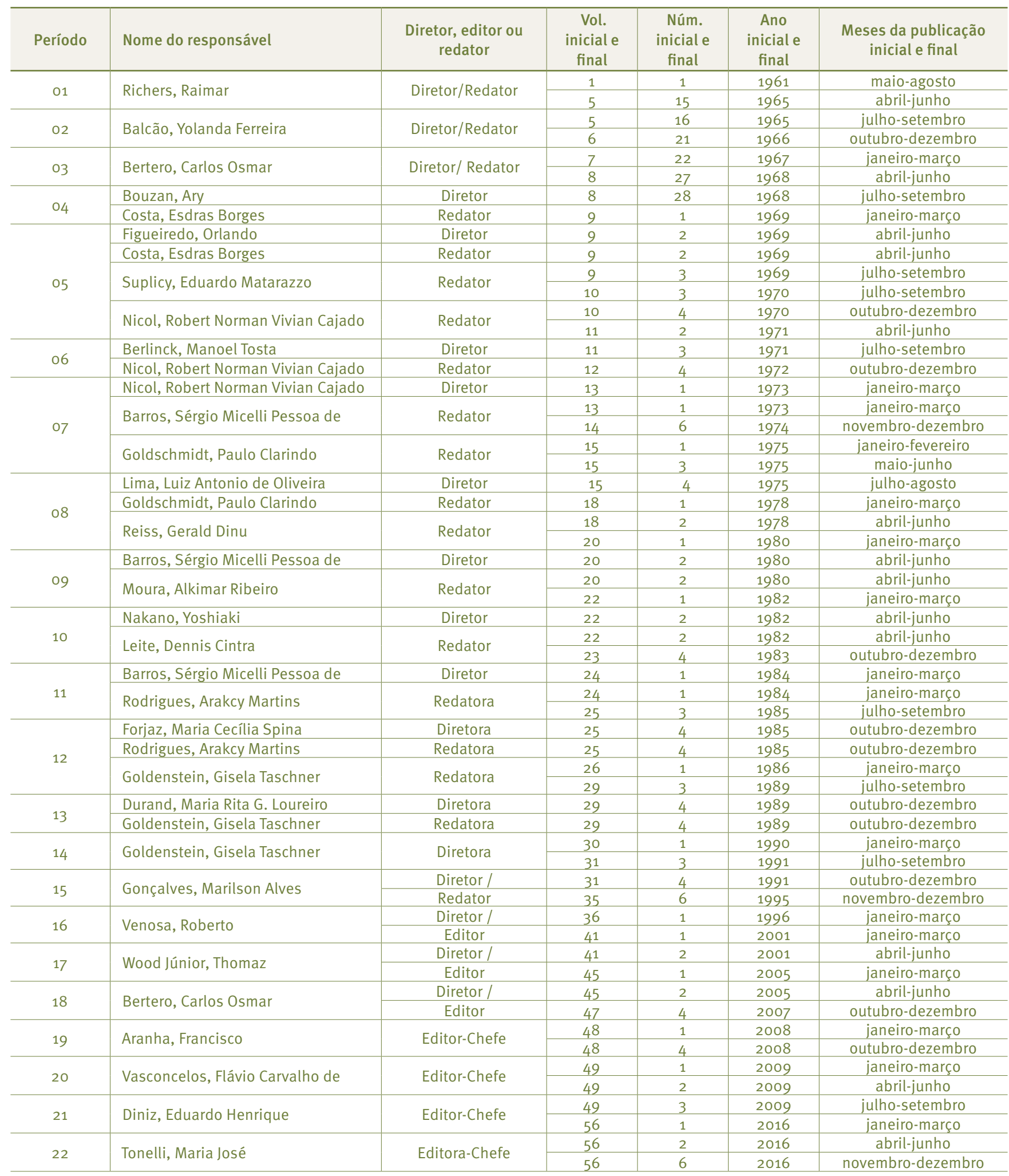


Da longa trajetória de existência da revista acompanhada durante o mapeamento deste artigo, alguns aspectos emergiram dos dados e puderam ser reportados nesta seção.

A partir da edição de janeiro/março de 2001 (volume 41, número 1), no final da gestão do diretor/editor Roberto Venosa, então sucedido pelo professor Thomaz Wood Júnior, além de passar a existir no periódico RAE a seção Fórum - considerada um espaço 'nobre' de publicação de materiais com praticamente a mesma relevância da seção Artigos, a revista passou a também publicar pensatas.

Entre 2001 e 2002, a RAEpublicações aumentou seu escopo de atuação, incluindo na sua coleção a RAE-eletrônica e a RAE-executivo, que mais tarde se tornou GV-executivo (Rosa \& Santos, 2012).

Em janeiro de 2010, a RAE passou a fazer parte do Social Sciences Citation Index (SSCI) e a constar no Journal Citation Reports/Social Sciences Edition (JCR) (Diniz, 2010), um importante indexador do meio acadêmico-científico que reúne coleções de periódicos do mundo todo e mensura anualmente seus fatores de impacto (JCR, 2017). A partir desse mesmo ano (volume 50), os artigos publicados no periódico também passaram a trazer o resumo em espanhol.

Do ano de 2011 (volume 51) em diante, a $R A E$ retomou a sua periodicidade bimestral, com a publicação de seis números anuais (SciELO Brasil, 2017a), ocorrendo nos meses de janeiro, março, maio, julho, setembro e novembro ( $R A E, 2017 \mathrm{a}, 2017 \mathrm{~b})$. Na edição de maio-junho de 2011 (volume 51, número 3), em texto do professor Bertero, são destacados os 50 anos da existência do periódico (Bertero, 2011), complementando fatos abordados alguns anos antes (Bertero, 2006).

Com a continuidade do processo de internacionalização da $R A E$, a revista realizou diversas ações para esse fim: a tradução do sistema de submissão, a participação de membros de instituições estrangeiras no comitê científico do periódico, a publicação de artigos em três idiomas, além da publicação de uma primeira edição totalmente em inglês (Diniz, 2015).

A partir da renovação do corpo editorial científico em 2014, fazendo elevar a participação de estrangeiros de $10 \%$ para $21 \%$, ocorreu um aumento da publicação de artigos na RAE de autores vinculados a instituições acadêmicas internacionais (Diniz, 2014). Tal movimento teve prosseguimento com a gestão dos professores Francisco Aranha, em 2008, e Flávio Vasconcelos, em 2009, e a longeva fase liderada por Eduardo Diniz. A internacionalização de periódicos brasileiros da área de Administração (Diniz, 2017) demonstra-se uma temática desafiadora.

A partir do segundo exemplar da RAE do ano de 2016, teve início o $22^{\circ}$ período de gestão editorial do periódico, tendo como editora-chefe a professora Maria José Tonelli, a sexta mulher a ocupar o cargo de gestor/gestora do conteúdo da revista, unindo-se ao grupo formado por, em ordem de assunção ao cargo: Yolanda Ferreira Balcão, Arakcy Martins Rodrigues, Maria Cecília Spina Forjaz, Gisela Taschner Goldenstein e Maria Rita G. Loureiro Durand.

Portanto, a elaboração deste estudo abrangendo todo o acervo da $R A E$, com a utilização de técnicas da bibliometria (Hood \& Wilson, 2001; Mingers \& Leydesdorff, 2015), de text mining (Feinerer, Hornik, \& Meyer, 2008; Hashimi, Hafez, \& Mathkou, 2015; Kayser \& Blind, 2017), da análise de rede social (Abbasi, Hossain, \& Leydesdorff, 2012; Zheng, Le, Chan, Hu, \& Li, 2016) e da análise geográfica (Câmara, Vinhas, Davis, Fonseca, \& Carneiro, 2009; Floriani, 1987; Francisco, 2011) justifica-se pelo interesse em compreender várias propriedades observáveis do acervo de publicações do periódico, entre elas: a quantidade dos diferentes tipos de documentos publicados, a passagem dos autores mais prolíficos pelo periódico, os períodos de ocorrência das publicações atrelados à variação da autoria, bem como a identificação de palavras mais frequentes e influentes nos documentos do acervo que refletissem a essência de seu conteúdo.

\section{PROCEDIMENTO DE COLETA E ANÁLISE DOS DADOS}

Os autores optaram pela exploração do acervo da $R A E$ disponibilizado via acesso ao repositório eletrônico de periódicos e revistas da Biblioteca Digital FGV EAESP (FGV, 2017b), em virtude de seu protocolo de dados aberto OAI-PMH de interoperabilidade entre repositórios digitais (OAI, 2017), o qual viabilizou a captura eletrônica automatizada da base de dados desse repositório digital, em detrimento de outros dois locais que também disponibilizam o acervo de publicações do periódico (RAE, 2017a; SciELO Brasil, 2017b).

A coleta de dados foi realizada em duas etapas, entre os meses de fevereiro e maio de 2017 , seguida de filtragens e tratamento técnico das informações. Os autores construíram robots com códigos scripts redigidos nas linguagens de programação Perl (The Comprehensive Perl Archive Network [CPAN], 2017; PERL, 2017) e R (R Core Team, 2017) para a realização da captura dos dados de maneira automatizada, buscando minimizar retrabalhos de digitação na preparação inicial da base de dados da pesquisa.

Foram alvo de exploração no estudo os documentos disponibilizados em língua portuguesa ao longo de 56 volumes completos publicados pelo periódico, ou seja, desde a sua edição 
inaugural, do ano de 1961 (volume 1, número 1), até a última edição do ano de 2016 (volume 56, número 6). 0 critério adotado na escolha dos documentos a serem coletados tomou como base a sua classificação no repositório eletrônico da Biblioteca Digital da FGV EAESP, seguindo determinadas categorias já padronizadas como setSpecs atribuídos pelo protocolo OAI-PMH (FGV, 2017a; OAl, 2017) para os documentos catalogados no acervo da $R A E$. Na primeira etapa da coleta, foram selecionados para compor o material de exploração da pesquisa os seguintes setSpecs: artigos (RAE:Artigos e RAE:RAE+-+Artigos), fórum (RAE:F\%C3\%Bzrum e RAE:FR), pensatas (RAE:Pensata), editoriais (RAE:Editorial) e resenhas (RAE:Resenha e RAE:RAE+-+Resenhas) - nesse procedimento, foi utilizado um código de script escrito pelos autores na linguagem de programação Perl (CPAN, 2017; PERL, 2017). Foi necessária a realização de uma segunda etapa de coleta de dados, pois um período de catalogação do acervo digital dos artigos compreendidos entre os volumes 36 (1996) e 44 (2004) utilizou outros 19 diferentes setSpecs como identificação dos documentos na biblioteca digital, além dos anteriormente informados.

Em seguida, com a integração das duas coletas do material do acervo, foi construída uma base de dados para ser utilizada na pesquisa, composta pelos campos: código do documento, língua do documento, título do documento, palavras-chave e resumo (quando existentes), nomes dos autores, ano, volume, número (exemplar), números das páginas da publicação, número de autores (distribuição da autoria), setName e setSpec OAI-PMH utilizado na captura, além de serem seguidos alguns passos complementares para o refinamento e ajustes técnicos dessa base de dados:

1. Todos os registros passaram por scripts de filtros de limpeza dos caracteres acentuados que apresentavam formatos não padronizados com a tabela ASCII e geravam caracteres não legíveis, realizando, dessa forma, todas as correções necessárias à padronização dos caracteres para a língua portuguesa;

2. Cada registro do banco de dados recebeu a identificação de um código único (dez números separados por dois blocos de cinco dígitos, por exemplo: 30994-29811), estes aproveitados do próprio acervo digital do repositório OAlPMH. Esse procedimento favoreceu a remoção de 167 registros duplicados e também de cinco registros que não possuíam o respectivo código único;

3. Em seguida, uma sequência de ajustes manuais foi realizada na base de dados da pesquisa, com intuito de separação dos documentos redigidos em português - objeto do estudo - dos demais documentos redigidos em outras línguas, por exemplo: inglês, francês ou espanhol, por intermédio do título do documento, palavras-chave e resumos, quando existentes;

4. Dessa forma, foi gerada uma base de dados integrada com 2.381 documentos, do período entre 1961 e 2016, resultando no total de: 1.422 documentos das seções Artigo e Fórum juntos - rotulada nesta pesquisa como “artigos (inclui fórum)", além de 217 editoriais, 62 pensatas e 680 resenhas;

5. Em seguida, procedeu-se ao download de cada arquivo PDF dos documentos identificados e à extração do conteúdo texto integral destes, com intuito de ampliação do corpus do conteúdo para ser explorado na pesquisa. Nessa etapa, um segundo robot criado pelos autores e escrito em código script na linguagem de programação R (R Core Team, 2017) foi utilizado para a automatização do procedimento de coleta via internet, com a extração, conversão e gravação do conteúdo de texto dos documentos.

6. Com a estruturação final da base de dados, foi possível adicionar uma segmentação temporal nos registros, utilizando rótulos de períodos (ou intervalos de tempo) a cada quatro, oito ou 14 anos (compreendidos nos limites de 1961 a 2016), com intuito de viabilizar análises temporais das informações coletadas, pelo agrupamento de períodos idênticos abrangendo o extenso intervalo dos 56 volumes completos cobertos no estudo.

Dessa forma, com a disponibilidade de todo o conteúdo de texto já extraído dos documentos (artigos incluindo fórum, pensatas, editoriais e resenhas), foi possível também explorar e analisar o acervo digitalizado do periódico RAE com ferramentas de software para análise estatística (Minitab, 2017; R Core Team, 2017), com a utilização de técnicas bibliométricas (Hood \& Wilson, 2001; Mingers \& Leydesdorff, 2015), de análise de conteúdo via text mining (Feinerer et al., 2008; Hashimi et al., 2015; Kayser \& Blind, 2017), da análise de rede social (Abbasi et al., 2012; Zheng et al., 2016) e da análise geográfica ou geoanálise (Câmara et al., 2009; Floriani, 1987; Francisco, 2011).

$\mathrm{Na}$ aplicação de tais técnicas nos diversos conteúdos analisados, os pesquisadores criaram um procedimento automatizado via código script de programação na linguagem $\mathrm{R}$ para identificação e remoção de palavras identificadas como stopwords (Dolamic \& Savoy, 2010) da língua portuguesa (exs.: artigos, pronomes, verbos de ligação, conjunções, alguns adjetivos etc.), além de tratar manualmente palavras não filtradas pelo algoritmo automatizado (exs.: anos, Paulo), que indicavam contexto/assuntos sem relação com os estudos centrais da grande área de conhecimento da Administração. 
A análise de conteúdo via text mining com o aproveitamento de recursos da biblioteca $t m$ do software $\mathrm{R}$ (Feinerer et al., 2008) permitiu gerar tabelas com a lista das 25 palavras mais frequentes localizadas no corpo integral dos textos das pensatas, editoriais e resenhas, ou em blocos parciais, dos títulos, resumos ou palavras chave dos artigos, o que propiciou a criação de figuras com "nuvens" formadas pelas palavras simples mais frequentes, e a utilização da Primeira Lei de Zipf (Piantadosi, 2014; Zipf, 1949) para verificar o valor da constante gerada pela equação $f . r=c$ para alguns casos.

A análise de conteúdo via SNA (Social Network Analysis) (Hanneman \& Riddle, 2005) permitiu a análise da colaboração entre autores dos artigos, destacando sua frequência de publicação em parceria (centralidade de grau) e sua importância no estabelecimento de ligações entre grupos de autores (centralidade de intermediação), além de outras propriedades. Da mesma forma, as palavras-chave foram analisadas, e a utilização dos modelos de superfície a partir da técnica de Triangular Irregular Networks (TINs) (Francisco, 2011; Huang,
1989) permitiu o mapeamento dos termos/assuntos de maior relevância utilizados na articulação dos conteúdos da $R A E$ durante toda a sua trajetória.

\section{IDENTIFICAÇÃO E DISCUSSÃO DOS RESULTADOS}

Com a utilização dos dados da pesquisa e do software Minitab (2017), foram criados os Gráficos 1, 2, 3.

\section{Artigos científicos - Totalização, médias e coautoria das publicações no periódico}

A publicação do primeiro artigo na $R A E$ contando com autoria única (Machline, 1961), assim como o primeiro artigo com dois autores (Motta \& Hopp, 1961), ocorreu no volume 1, número 1, de maio-agosto de 1961 - a edição de lançamento do periódico (FGV, 1961).

Gráfico 1. Quantidade total de números da $R A E$ e quantidade total de artigos publicados no periódico (inclui fórum), disponibilizados conforme o volume da publicação - do volume 1 (ano de 1961) até o volume 56 (ano de 2016)

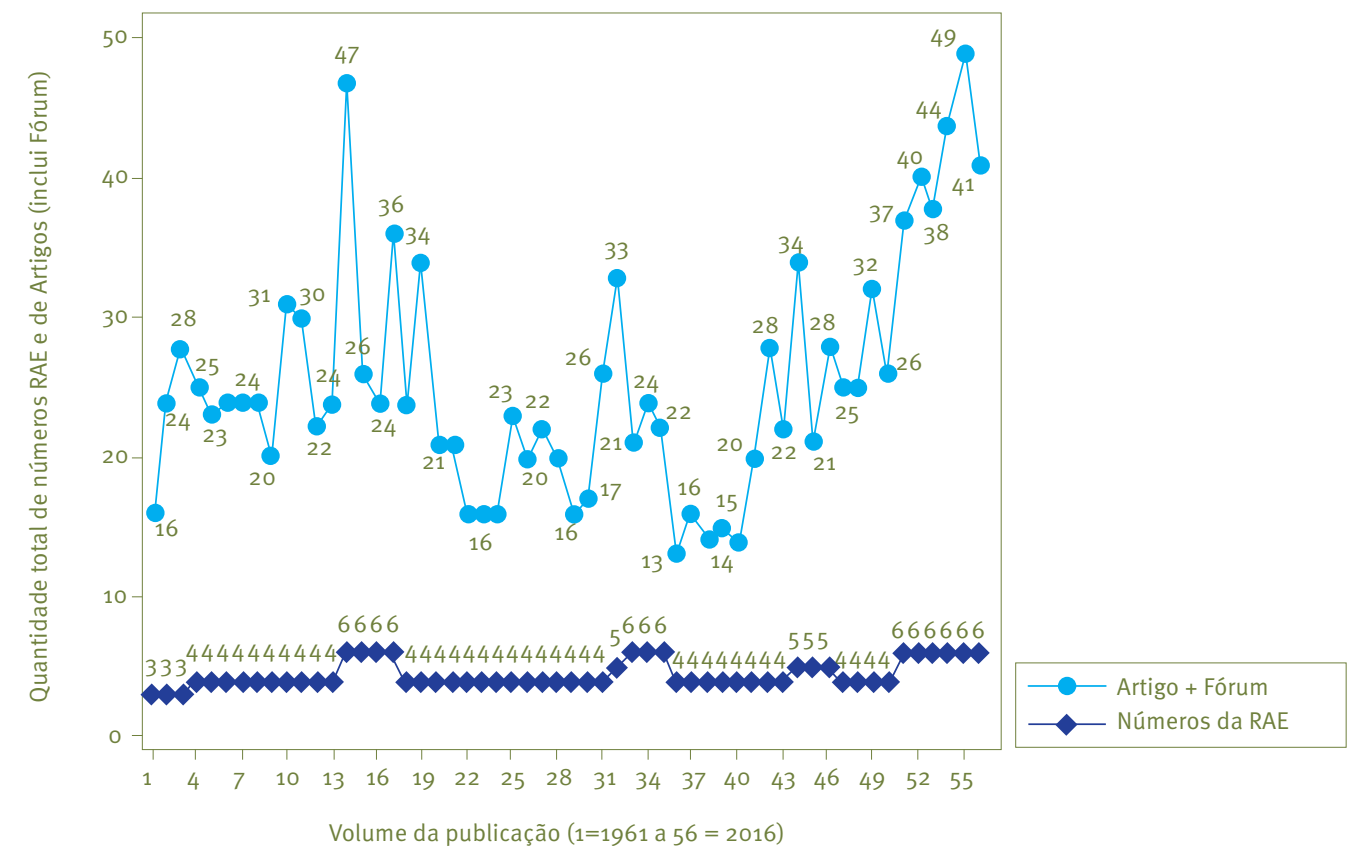

Nota: entre 1961 a 1963, os volumes de 1 a 3 representaram parcialmente diferentes anos, mas neste gráfico foram totalizados associados a um único respectivo ano (ex: $1961=$ volume 1$)$

O Gráfico 1 apresenta a quantidade total de artigos publicados na RAE (incluindo aqueles da seção Fórum) e a quantidade de números (das edições) da RAE de acordo com o volume da publicação, desde o início do ano de 1961 (volume 1, número 1) até o ano de 2016 (volume 56, número 6). Percebe-se que, no decorrer do tempo, a RAE passou por oscilação do número total de artigos publicados anualmente, com o mínimo de 13 publicações, no volume 36 (ano de 1996, início da gestão do professor 
Roberto Venosa), e o máximo de 49 artigos, no volume 55 (ano de 2015, final da gestão do professor Eduardo H. Diniz). Vale destacar um segundo pico máximo, conforme o Gráfico 1, que informa 47 artigos publicados no ano de 1974 (volume 14). Na parte inferior do Gráfico 1, também é informada cada uma das quantidades de números (edições), vinculados ao respectivo volume, disponibilizados anualmente na RAE. Percebe-se que a quantidade de edições anuais do periódico variou entre três e seis de 1961 até 2016, e os dois picos máximos de quantidade de artigos publicados no periódico ocorreram em volumes (ou anos) que apresentaram seis números (edições) naquele respectivo ano.

A primeira publicação de um artigo na $R A E$ com a assinatura de três autores ocorreu no ano de 1965, intitulado “Treinamento industrial em São Paulo”, de Antônio Guimarães,
David Missel e Oscar Zunder, publicado no volume 5, número 16 (Guimarães, Missel, \& Zunder, 1965) - até o ano de 1988, apenas o total de nove artigos foi produzido com essa mesma quantidade de autores. 0 artigo "Microeletrônica e organização do trabalho no setor de serviços", do ano de 1985 , volume 25 , número 4 (Rodrigues, Barbosa, Luz, \& Kilimnik, 1985), inaugurou a participação de quatro autores entre as publicações científicas do periódico. Outros artigos publicados no periódico contendo cinco autores (Martes, Bulgacov, Nascimento, Gonçalves, \& Augusto, 2006), seis autores (Comassetto et al., 2013) e nove autores (Tigre et al., 2011) ocorreram inicialmente nos anos de 2006, 2013 e 2011, respectivamente. Tal evolução da quantidade de artigos publicados na $R A E$, associada com a variação da autoria dos mesmos, está ilustrada no Gráfico 2.

Gráfico 2. Quantidade total de artigos publicados na $R A E$ (inclui fórum) conforme a variação da autoria (de único autor até 9 autores), em períodos de 14 anos, de 1961 até 2016
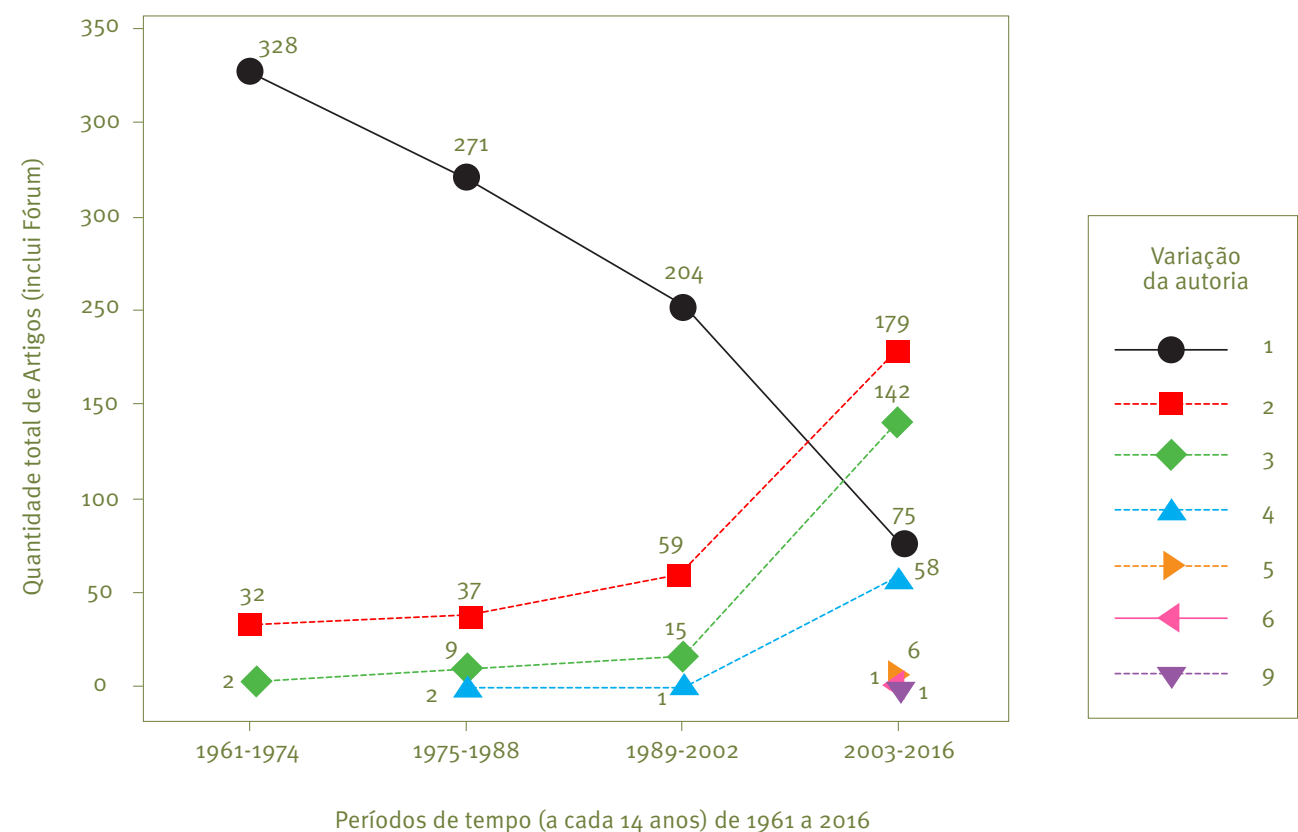

Períodos de tempo (a cada 14 anos) de 1961 a 2016

O Gráfico 2 ilustra o comportamento da quantidade de artigos publicados no periódico RAE conforme a variação da autoria na redação desses artigos, em quatro períodos de 14 anos, entre 1961 e 2016.

É percebido o decréscimo acentuado da quantidade de artigos publicados no periódico contando com a autoria de único autor - enquanto, entre 1961 e 1974, foi publicado um total de 328 artigos com autoria única (90,6\% do total do período), no período de 2003 a 2016, os artigos com único autor ficaram reduzidos ao total de 75 artigos (16,2\% do total do período). As quantidades de artigos que traziam autoria de dois autores ( 59 artigos) ou três (15 artigos) no período de 1989 a 2002 (representando juntas $26,5 \%$ das publicações do período) passaram respectivamente a totalizar 179 e 142 artigos quando observados no período entre 2003 e 2016 (representando juntas $69,5 \%$ das publicações do período), demonstrando um aumento significativo da publicação de artigos em colaboração na $R A E$ nesse último período. 
No ano de 2012, ocorreu, pela primeira vez na história da revista, a publicação de apenas um artigo contando com autoria única durante o ano todo - ocorrido no volume 52, número 3 - “Flexibilidade e modelagem de processos de negócio: Uma relação multidimensional" (Albuquerque, 2012).

Para refinar ainda mais a percepção do incremento da publicação do número de artigos (incluindo fórum) em coautoria ao longo dos volumes da RAE, foram observados os 14 períodos divididos a cada quatro anos (de 1961 a 2016) a respeito do comportamento da média dessas publicações, associado com a variação da autoria, conforme Gráfico 3.

Gráfico 3. Quantidade média de artigos publicados na $R A E$ (inclui fórum) por ano, conforme a variação da autoria (de único autor até 9 autores), e em períodos de quatro anos, de 1961 até 2016

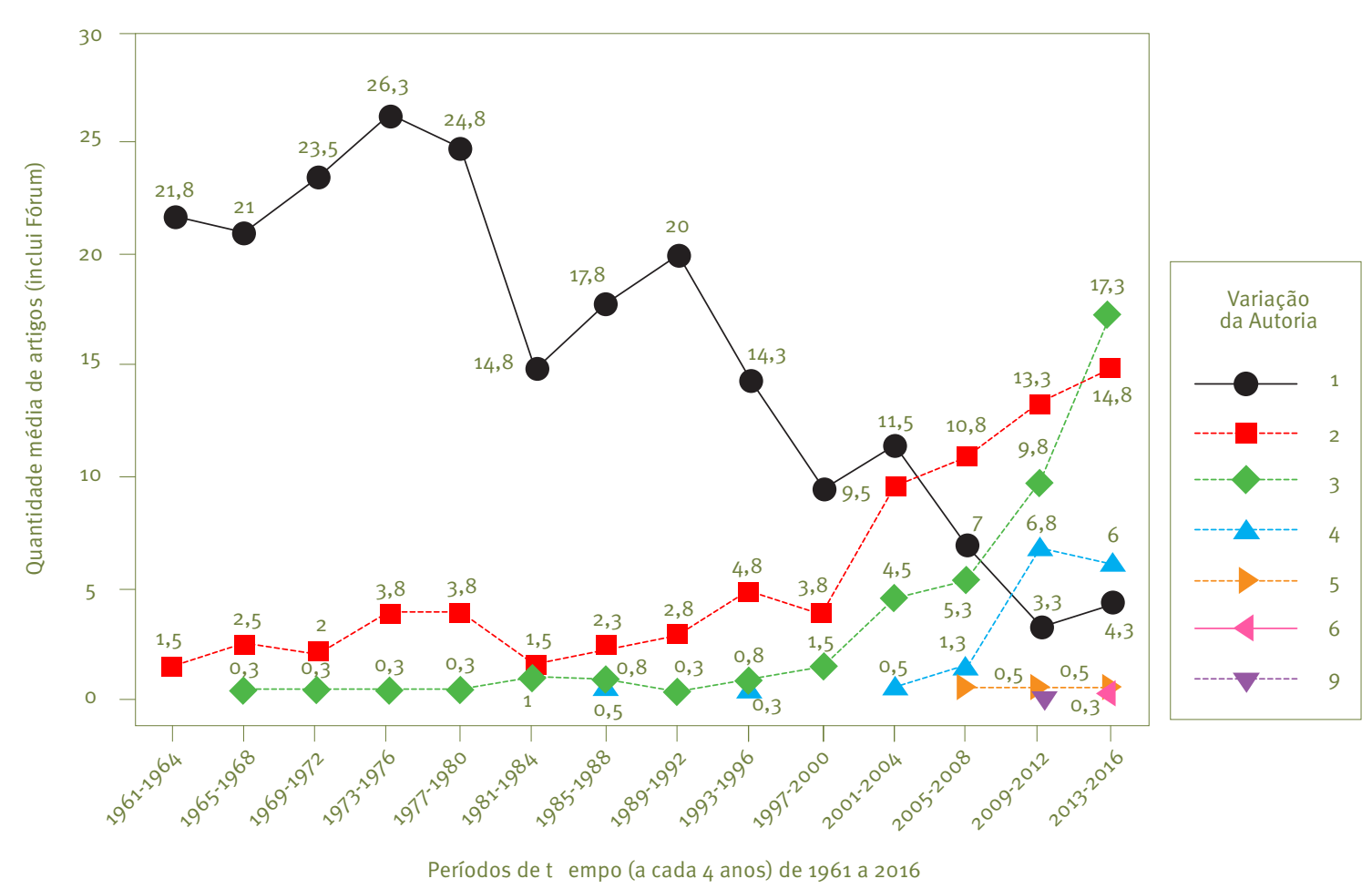

O Gráfico 3 mostra da quantidade média de artigos publicados na $R A E$ (inclui fórum) por ano, conforme a variação da autoria (de único autor até nove autores), e em períodos de quatro anos, de 1961 até 2016, representados por 14 intervalos.

Até o ano de 2008, o máximo de variação de autoria dos artigos publicados no periódico havia atingido cinco autores. Nota-se, nos dados da pesquisa, que a publicação de um artigo com nove autores (Tigre et al., 2011), no período de 2009 a 2012, especificamente no ano de 2011 , volume 51 , número 1 , ocorreu antes da publicação do primeiro artigo no periódico com a autoria de seis autores (Comassetto et al., 2013), ocorrida somente entre 2013 e 2016.

Outra percepção observada no Gráfico 3 é o salto da média de publicação de artigos com a autoria de três autores, de 4,5 artigos/ano (17,3\% das publicações) no período de 2001 a 2004 para 17,3 artigos/ano (40,1\% das publicações) no período de 2013 a 2016, superando até mesmo, nesse último período, as médias de artigos publicados com dois autores (14,8 artigos/ano), além daqueles com autoria única (média de 4,3 artigos/ano).

O Gráfico 4 também destaca o incremento da coautoria no período de 2001 a 2016, segmentado em intervalos de quatro anos. Fica evidenciado que a mediana anual da publicação de artigos (inclui fórum) contando com a autoria de três autores (de 16,5), entre 2013 e 2016, tornou-se muito superior aos valores identificados nos demais períodos anteriores desse mesmo gráfico: nos períodos de 2001 a 2004 e 2005 a 2008 com mediana de cinco artigos anuais e no período de 2009 a 2012 com mediana de 6,5 artigos anuais, demonstrando que o periódico $R A E$ passou a priorizar publicações de artigos contendo a autoria (colaboração) de um número maior de autores no último período de quatro anos avaliado neste estudo. 
Gráfico 4. Distribuição anual da quantidade de artigos publicados na RAE (inclui fórum) conforme a variação da autoria (de único autor até 9 autores) e agrupados por intervalos de tempo a cada quatro anos, entre 2001 e 2016

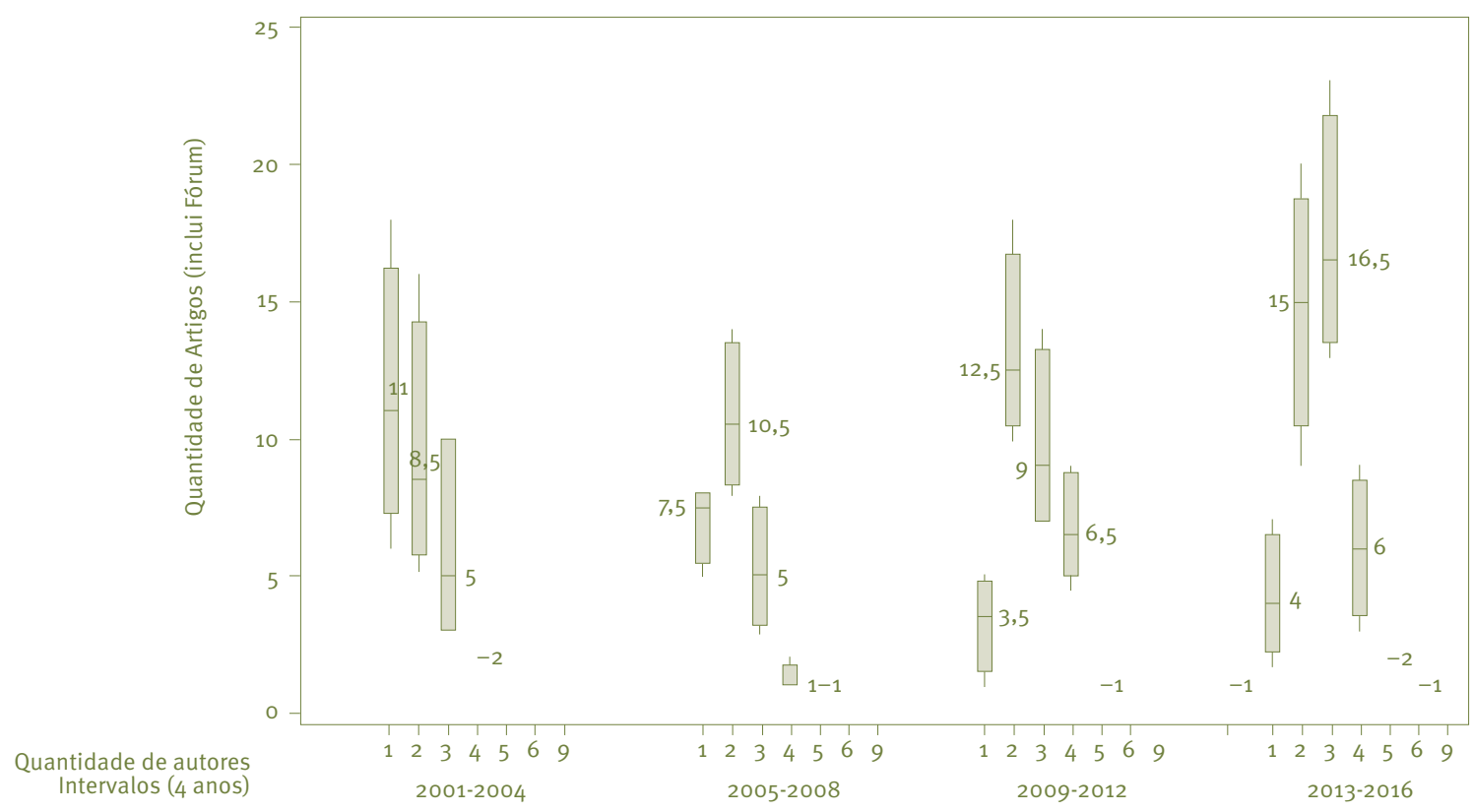

Variação de autoria conforme períodos de tempo (2001 a 2016)

\section{Artigos científicos - Autores mais prolíficos}

Para ilustrar com mais detalhamento a lista dos autores mais prolíficos na publicação de artigos no acervo da RAE entre 1961 a 2016, foi construída a Tabela 1.

0 autor Heinrich Rattner (que também assinava seus artigos com o nome Henrique Rattner) é considerado o autor mais prolífico nos 56 volumes completos publicados pela $R A E$, possuindo um total de 28 artigos publicados no periódico, com a primeira publicação ocorrendo no ano de 1964 e a última, no ano de 1987, conforme a Tabela 1. Esse autor publicou 27 artigos como primeiro (e único) autor e apenas um artigo como segundo autor, em coautoria com outros dois colaboradores - Claude Machline e Olivier Udry.

Classificado na segunda posição pela quantidade de artigos publicados no periódico de 1961 a 2016, destaca-se o professor Carlos Osmar Bertero, com um total de 20 artigos publicados, dos quais 16 foram como primeiro autor e quatro como segundo autor. 0 professor Bertero possui a longevidade de 49 anos de publicação na $R A E$ - no período compreendido entre 1966 e 2014 - contando com a colaboração de seis outros autores: Rafael Alcadipani, Marcelo Pereira Binder, Tania Margarete Mezzomo Keinert, Alberto de Oliveira Lima Filho, Flávio Carvalho de Vasconcelos e Thomaz Wood Júnior, em seis de suas publicações, cinco delas com apenas um coautor adicional e uma delas com mais três coautores. 0 autor Fernando Claudio Prestes Motta publicou 19 artigos no periódico, sempre como primeiro autor. Outros três autores o sucederam nessa classificação, com o mesmo número de 17 publicações de artigos: Claude Machline, Raimar Richers e Luiz Carlos Bresser Pereira. 0 autor João Bosco Lodi publicou 11 artigos de 1966 a 1972, sem qualquer coautoria, e o autor Dayr Américo dos Reis, de 1964 a 2000, publicou nove artigos, três deles em coautoria. 
Tabela 1. Autores mais prolíficos na publicação de artigos no periódico, de 1961 a 2016

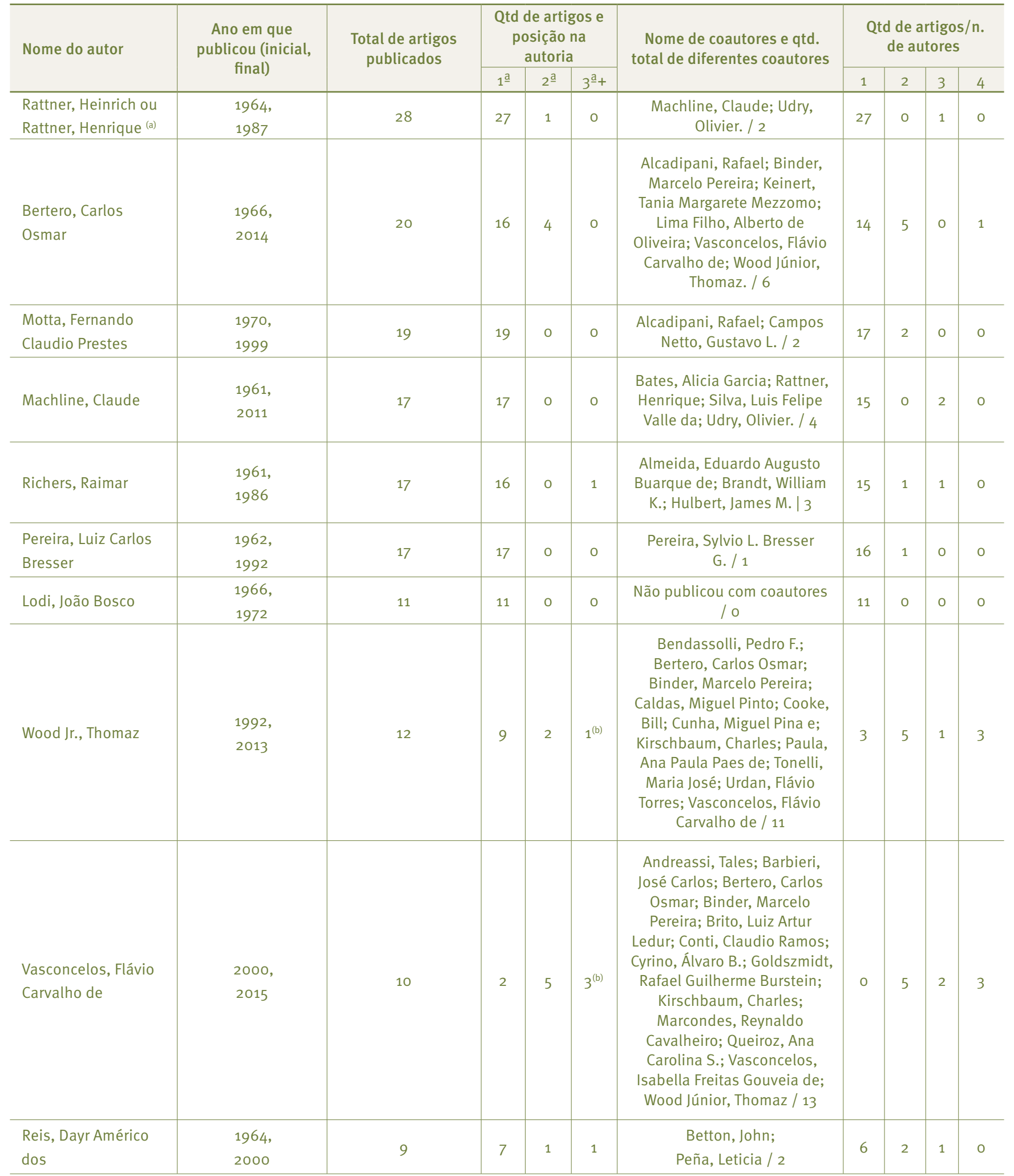

Notas: (a) o mesmo autor é descrito no acervo da revista com dois nomes diferentes; (b) é o quarto autor em uma única publicação 
Figura 1. Nuvem (word cloud) formada pelos nomes de autores mais prolíficos na publicação de artigos no periódico $R A E$, com o mínimo de cinco artigos publicados, no período de 1961 a 2016

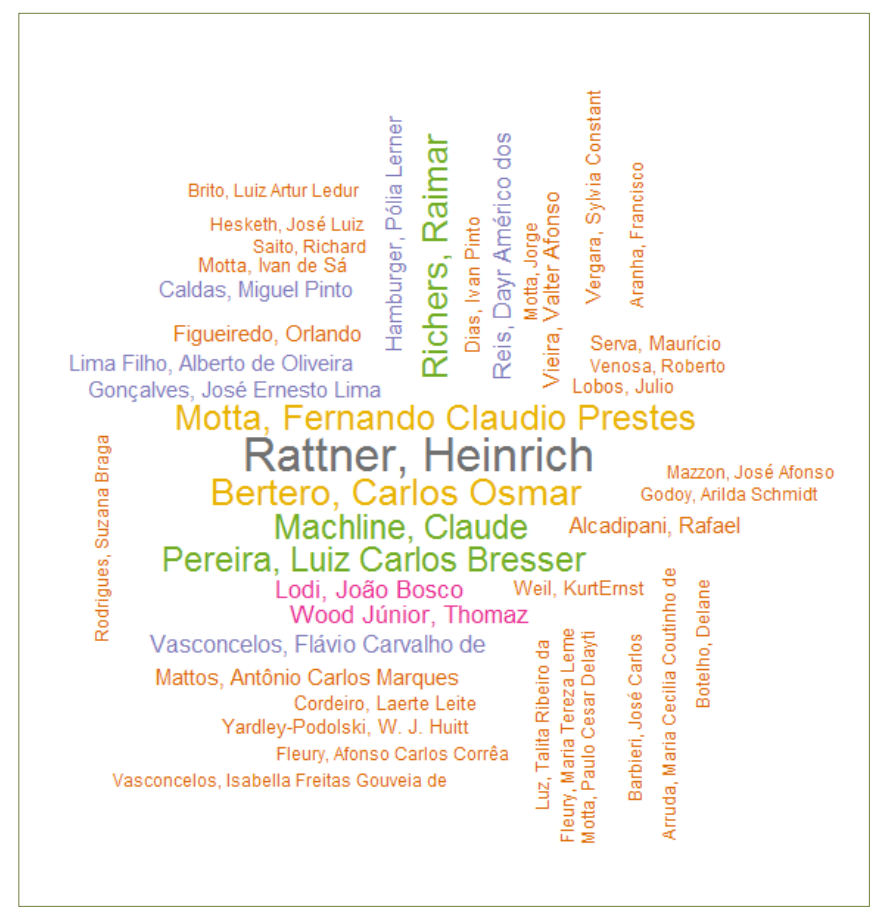

A Figura 1 mostra a imagem de uma "nuvem" formada pelos 43 nomes dos autores que mais publicaram artigos (incluindo fórum) no acervo do periódico RAE entre os anos de 1961 e 2016. 0 incremento no tamanho da fonte está associado à quantidade maior de publicações do autor, variando de 28 (máxima) até cinco (mínimo), pelo critério adotado na pesquisa na construção dessa imagem.

\section{Artigos científicos - Análise da rede de coautoria}

Os 1.422 artigos foram escritos por 1.571 autores únicos. Destes, 444 escreveram apenas artigos de um único autor. Os demais 1.127 realizaram coautorias e estão representados no Gráfico 5, que apresenta a topologia da rede (1-mode), desenhada a partir do tradicional algoritmo de Fruchterman e Reingold (1991), que apresenta, de maneira central, os elementos de maior grau e intermediação. Os 1.127 nós (autores) estão representados, interligados por 1.229 arestas. Cada aresta representa a realização de um ou mais artigos em parceria pelos nós (autores) de suas extremidades. A centralidade de grau (ou simplesmente grau) refere-se ao número de parcerias realizadas por cada autor.
A rede completa apresenta 762 componentes. Desconsiderando os 444 autores únicos (i.e., componentes com apenas um autor), as demais apresentam dois autores (164 componentes), três (85), quatro (32), cinco (19), seis (6), oito (2), nove (5), 13 (2), e três componentes principais - o maior com 141 autores (12,5\% da rede), o segundo com 34 (3,0\%) e um terceiro com 23 (2,0\%). 0 componente principal está detalhado no Gráfico 5 , com seus nós de maior grau ou intermediação nomeados.

Os autores de maior centralidade de grau e de intermediação de todo o acervo fazem parte do componente principal - Flávio Carvalho de Vasconcelos (10 artigos e grau 18), Thomaz Wood Júnior (12 artigos e grau 16), José Afonso Mazzon (5 artigos e grau 11) e Isabella Freitas Gouveia de Vasconcelos (5 artigos e grau 11). Destacam-se também na rede, pela produção, Carlos Osmar Bertero (20 artigos) e Fernando Carlos Prestes Motta (19 artigos).

Vale destacar que outros autores muito prolíficos, como Henrique (ou Heinrich) Rattner, com 28 artigos, Claude Machline, Raimar Richers e Luiz Carlos Bresser Pereira (ambos com 17 artigos), pertencem a componentes com menos associação de autoria, conforme já exposto, e, portanto, apresentam menor intermediação.

A Tabela 2 apresenta a centralidade de grau e de intermediação dos 80 principais autores de artigos (inclui fórum) da $R A E$, de acordo com os critérios de intermediação, grau e frequência de publicações, em ordem decrescente.

\section{Artigos científicos - Palavras mais frequentes nos títulos, resumos e palavras-chave}

De um total de 1.422 artigos (inclui fórum) publicados no periódico de 1961 a 2016, 721 artigos informaram resumos de seu conteúdo e 687 artigos incluíram uma lista de palavras-chave (explícitas) em seu conteúdo. Com a utilização da técnica de análise de conteúdo via text mining, foi possível gerar a Tabela 3 trazendo as 25 palavras simples mais frequentes localizadas nos títulos, resumos e palavras-chave de tais documentos e a criação das Figuras 2, 3 e 4 com as "nuvens" formadas pelas palavras simples mais frequentes.

\section{Artigos científicos - Rede das palavras-chave e análise geográfica por período}

Foram realizadas análises das palavras e conceitos mais mencionados nos artigos do acervo da RAE. As análises abordaram os títulos, as palavras-chave e os resumos dos artigos, e circunscreveram-se ao conteúdo em português da revista. 
Os 1.422 artigos analisados continham, no total, 3.356 ocorrências de palavras-chave. Foram, notadamente, 2.383 palavraschave únicas, mantido apenas o critério de não diferenciar letras maiúsculas e minúsculas - palavras no singular e no plural foram mantidas diferentes. As 50 palavras-chave mais frequentes, todas com seis ou mais ocorrências, são apresentadas na Tabela 4 .

Gráfico 5. Rede de associações entre autores de artigos (incluindo fórum) do periódico RAE, com destaque para 0 componente principal

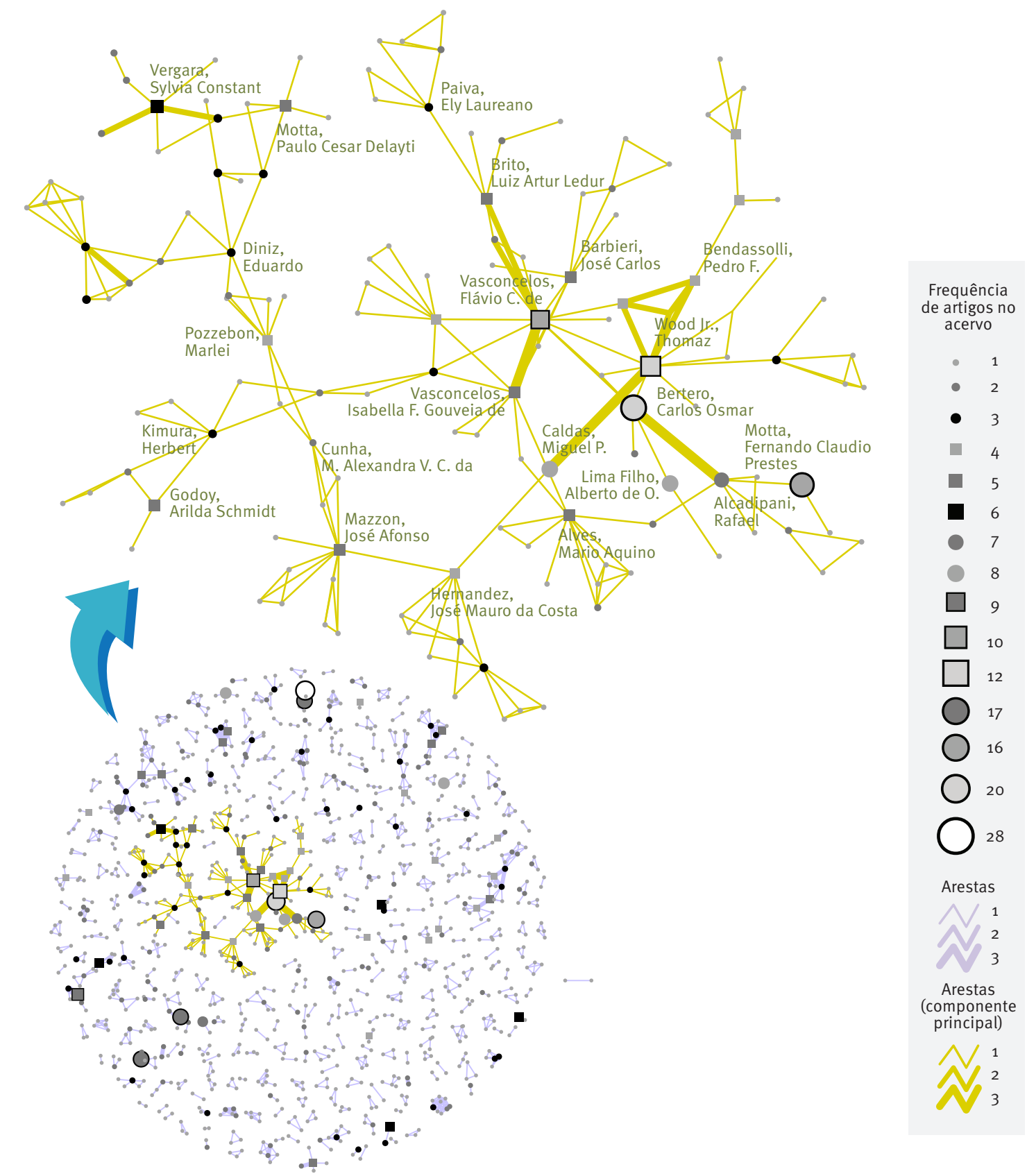

Nota: Os 141 autores do componente principal estão interligados por 219 arestas. 
Tabela 2. Frequência, centralidade de grau e de intermediação dos 80 principais autores no periódico RAE

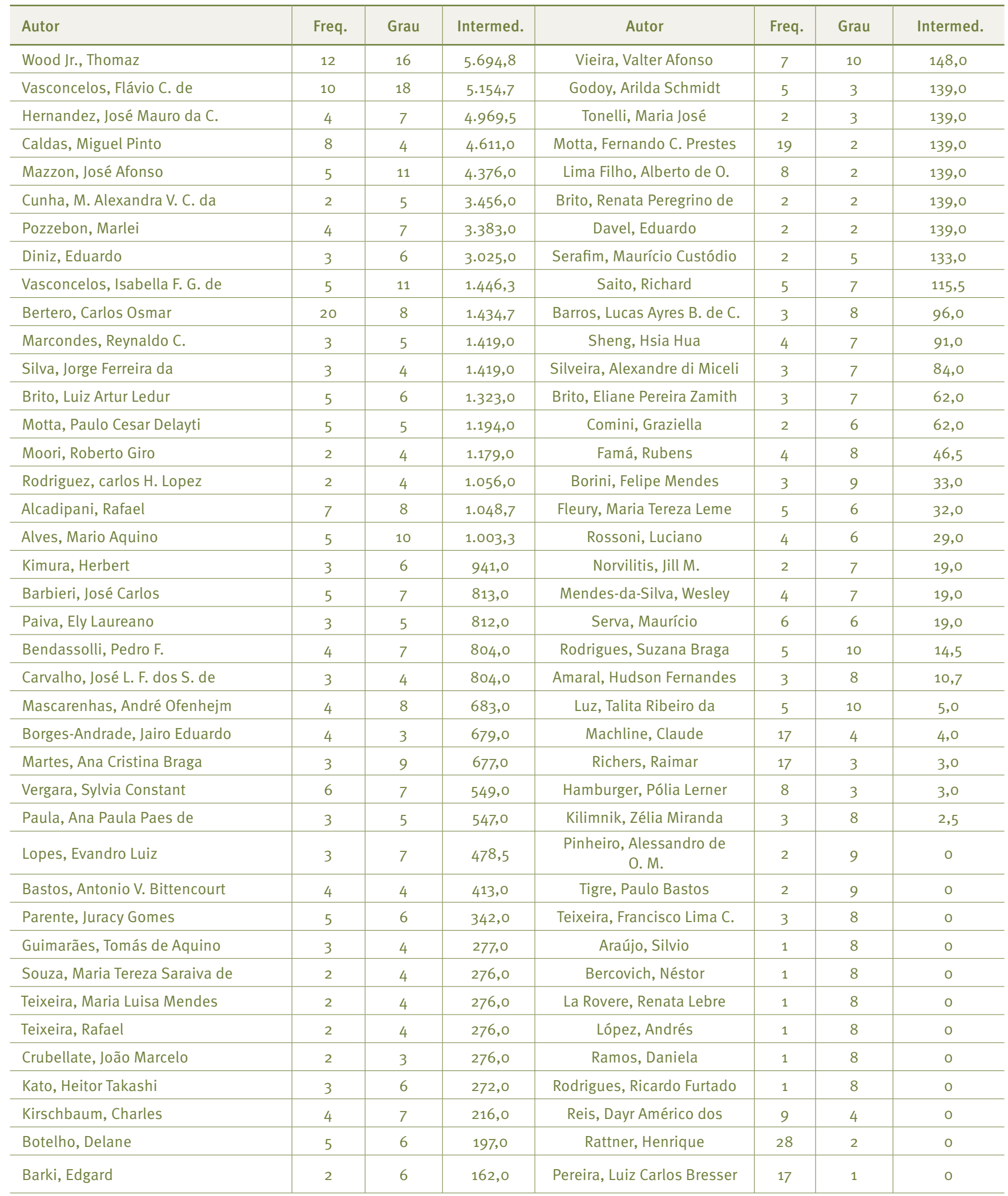

Nota: Os critérios de priorização foram intermediação, grau e frequência de publicação, em ordem decrescente de apresentação. 
Tabela 3. Lista ordenada das 25 palavras simples com a ocorrência mais frequente nos artigos (inclui fórum), conforme três diferentes campos de informação: nos títulos, nos resumos e nas palavras-chave, no período entre 1961 e 2016

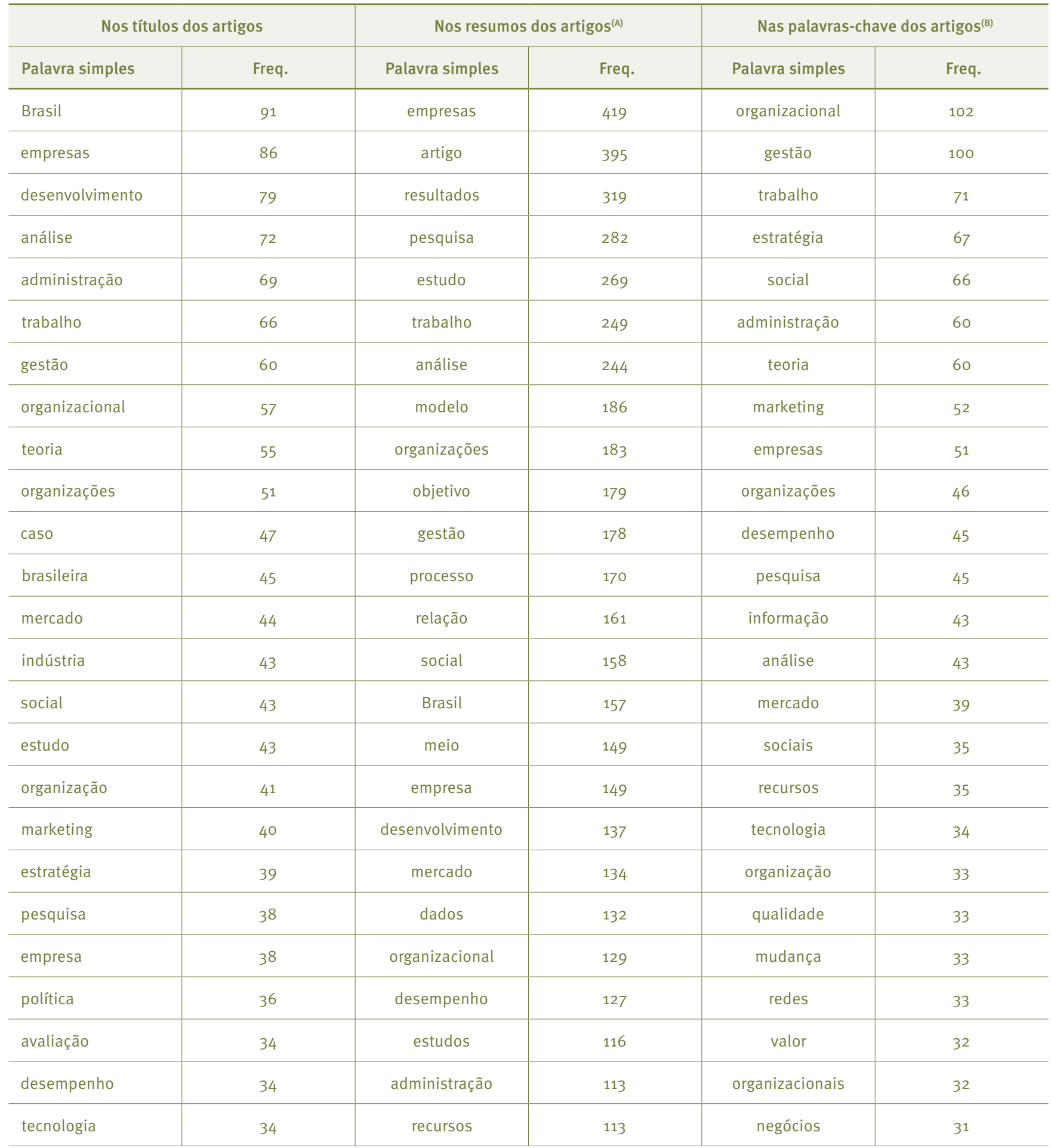

Nota: No total de 1.422 artigos publicados no periódico no período informado, (a) 721 artigos informaram resumos de seu conteúdo e (b) 687 artigos disponibilizaram uma lista de palavras-chave explícitas em seu conteúdo, de 1988 a 2016. 
Figura 2. Nuvem (word cloud) de palavras simples mais frequentes nos títulos dos artigos (inclui fórum) da RAE, com o mínimo de três ocorrências, no período entre 1961 e 2016

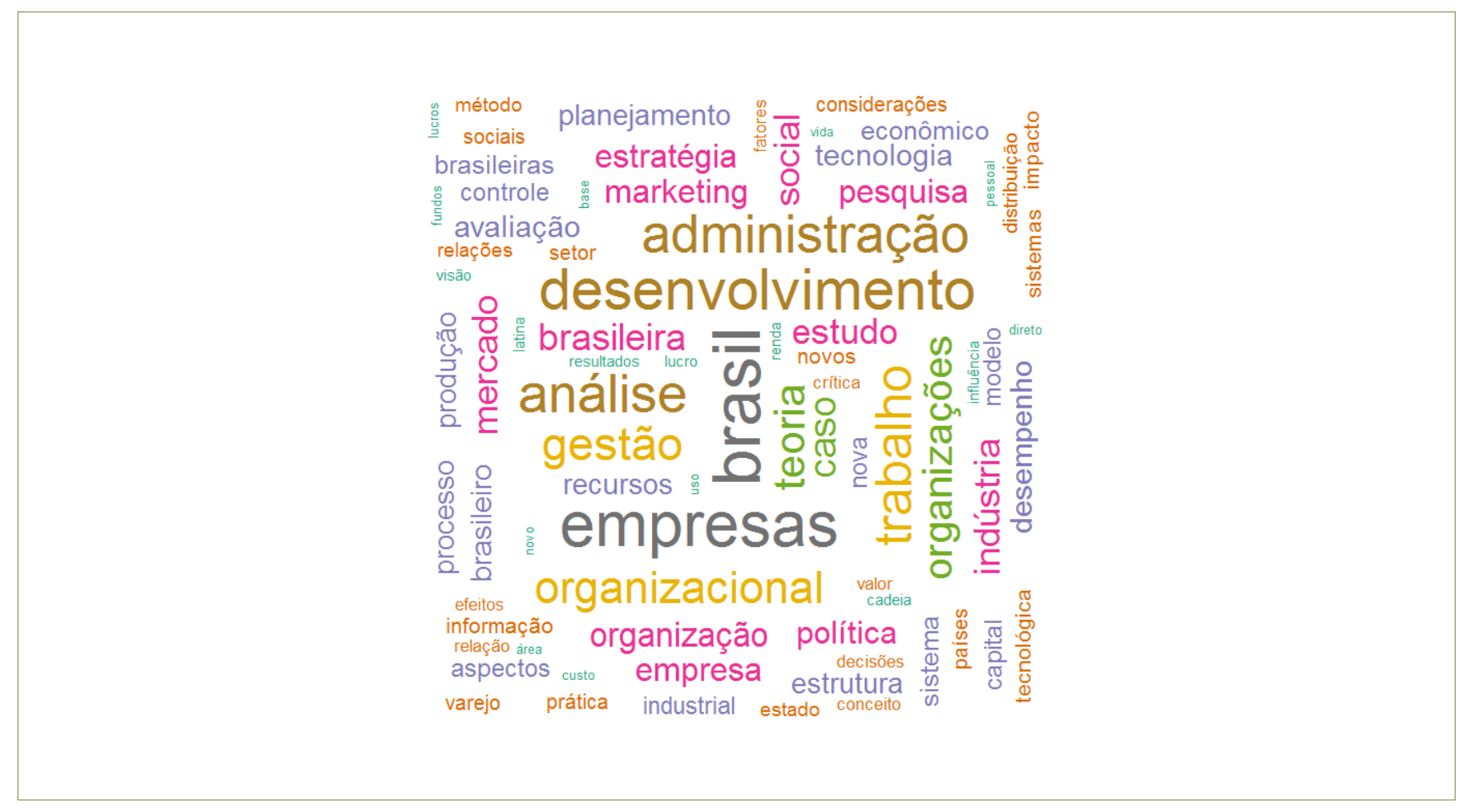

Figura 3. Nuvem (word cloud) de palavras simples mais frequentes nos resumos dos artigos (inclui fórum) da $R A E$, com o mínimo de três ocorrências, no período entre 1989 e 2016

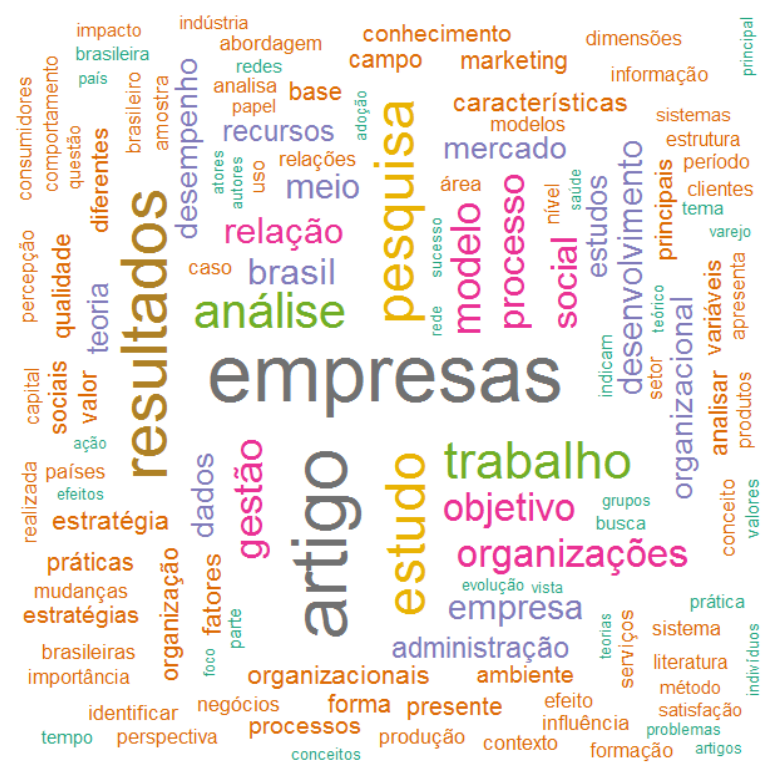


Figura 4. Nuvem (word cloud) de palavras simples mais frequentes nas palavras-chave dos artigos (inclui fórum) da $R A E$, com o mínimo de três ocorrências, no período entre 1989 e 2016

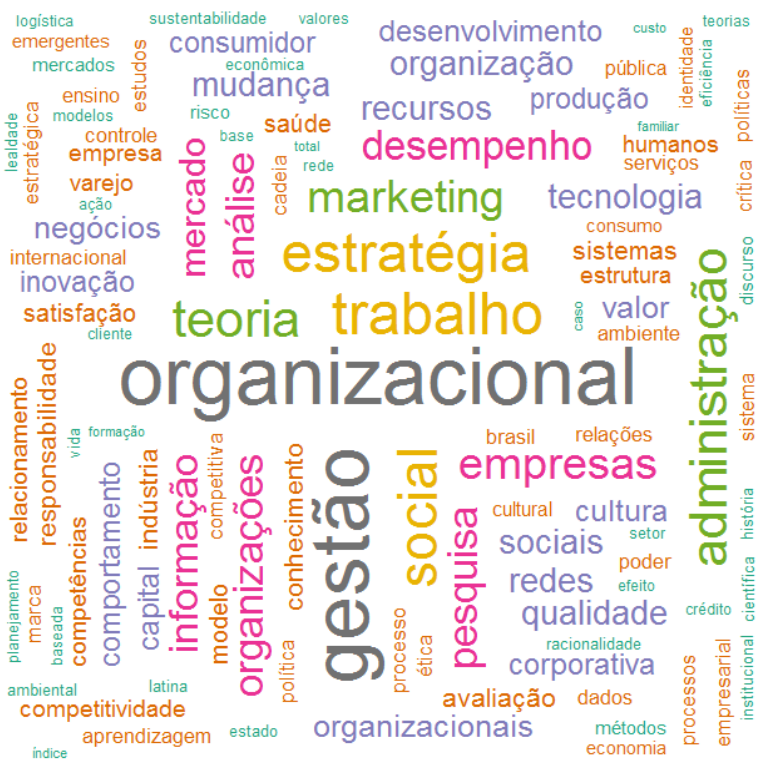

Tabela 4. As 50 palavras-chave mais frequentes no periódico RAE de 1961 a 2016

\begin{tabular}{|c|c|c|c|c|c|}
\hline Palavra-chave & Freq. & Palavra-chave & Freq. & Palavra-chave & Freq. \\
\hline inovação & 17 & poder & 9 & mercados emergentes & 7 \\
\hline mudança organizacional & 17 & recursos humanos & 9 & responsabilidade social & 7 \\
\hline competitividade & 16 & tecnologia & 9 & administração & 6 \\
\hline comportamento do consumidor & 15 & cultura & 8 & análise de redes sociais & 6 \\
\hline organizações & 14 & estudos organizacionais & 8 & aprendizagem organizacional & 6 \\
\hline vantagem competitiva & 14 & internet & 8 & capital social & 6 \\
\hline marketing & 13 & produção científica & 8 & estratégia empresarial & 6 \\
\hline desempenho & 11 & $\begin{array}{c}\text { responsabilidade social } \\
\text { corporativa }\end{array}$ & 8 & qualidade & 6 \\
\hline América Latina & 10 & sustentabilidade & 8 & serviços & 6 \\
\hline cultura organizacional & 10 & teoria das organizações & 8 & tecnologia da informação & 6 \\
\hline empreendedorismo & 10 & teoria institucional & 8 & teoria crítica & 6 \\
\hline satisfação & 10 & trabalho & 8 & teoria organizacional & 6 \\
\hline gestão de pessoas & 9 & governança corporativa & 7 & & \\
\hline
\end{tabular}


A rede completa de associação entre palavras-chave apresenta 124 componentes. O principal, destacado no Gráfico 6, apresenta 1.771 (74,3\%) palavras-chave (nós conectados), o que indica grande conexão entre os conceitos durante a extensa trajetória de publicação da revista. A densidade de rede é de 0,00236 . Os demais componentes apresentam de dois a 13 nós - a maioria com cinco (70 componentes) ou quatro nós (25 componentes). Essa configuração é similar para os períodos de 14 anos comparados. De 1989 a 2002, a rede apresentava 89 componentes, e o componente principal continha 728 nós $(63,9 \%)$. De 2003 a 2016, a rede apresentava 83 componentes, e o componente principal continha 982 nós $(68,5 \%)$.

No período de 1989 a 2002 (335 artigos incluindo fórum), foram publicadas 1.139 palavras-chave distintas, e, no período de 2003 a 2016 (406 artigos incluindo fórum), foram 1.434 palavraschave, das quais apenas 190 foram reutilizadas - 1.244 são termos novos. As redes apresentam 3.045 arestas no período de 1989 a 2002 e 3.671 arestas no período de 2003 a 2016. Seus componentes principais estão representados comparativamente na parte inferior do Gráfico 6.

As 10 palavras-chave com maior centralidade de grau (número de arestas ligadas a cada nó, ou número de associações de cada palavra-chave) foram, em ordem decrescente, "estratégia", "competitividade”, “mudança organizacional”, "inovação”, “vantagem competitiva”, “comportamento do consumidor”, "Brasil”, “organizações”, “marketing” e "varejo”. As três primeiras mantêm-se como as de maior grau no período de 1989 a 2002, época em que outras quatro palavras sobressaem: "cultura organizacional”, "globalização", "poder" e "recursos humanos”.

Já no período de 2003 a 2016, "estratégia”, "inovação”, "varejo" e "comportamento do consumidor" continuam sendo temas recorrentes, porém seis palavras-chave sequer utilizadas até então passaram a integrar a lista das 14 mais frequentes (i.e., com grau igual ou superior a 32): "internacionalização", “lealdade”, "sustentabilidade”, "produção científica”, "redes sociais", "confiança” e "responsabilidade social corporativa”. Integram ainda essa lista: "desempenho", "empreendedorismo" e "satisfação". Vale notar que "cultura organizacional” e "globalização" não mais foram utilizadas como palavraschave a partir de 2003. "Globalização" parece ter dado lugar a "internacionalização" no contexto das discussões da RAE. 0 papel que a internacionalização teve na trajetória recente da $R A E$ é também destacado por Diniz (2017) na pensata desta edição.

A Tabela 5 apresenta as centralidades de grau e de intermediação das palavras-chave mais importantes para 0 acervo da RAE. A centralidade de intermediação, ou betweenness centrality, apura a capacidade de intermediação de uma palavra- chave em sua relação com as demais, servindo como ponte para a interação entre elas (Hanneman \& Riddle, 2005).

As palavras-chave com maior centralidade de intermediação são, em ordem decrescente, “estratégia”, “Brasil”, “mudança organizacional”, "competitividade", "comportamento do consumidor” e "inovação”. As palavras “estratégia”, “mudança organizacional" e "competitividade" mantêm forte intermediação no período de 1989 a 2002, juntamente com "cultura organizacional" e "globalização". No período de 2003 a 2016, por sua vez, “estratégia”, “inovação”, “comportamento do consumidor” e "Brasil” mantêm forte intermediação, mas perdem em intensidade para “desempenho" e "teoria institucional”. As palavras “varejo", “internacionalização" e "governança corporativa” também se destacam quanto a essa medida de centralidade.

Buscou-se construir uma representação geográfica tridimensional da rede pelo uso da técnica de análise espacial TIN, que consiste na construção de superfícies com base em uma rede de triângulos não sobrepostos (Floriani, 1987; Huang, 1989). O emprego de técnicas de análise geográfica (ou geoanálise) em estudos bibliométricos continua incipiente na literatura científica nacional, desde que essa técnica e discussão foram mencionadas em artigo na RAE no ano de 2011 (Francisco, 2011).

Além da percepção visual da distribuição espacial das palavras-chave, é muito útil traduzir os padrões existentes em considerações objetivas e mensuráveis, que são endereçadas pela análise espacial de dados geográficos e pela estatística espacial. A ênfase da análise espacial é mensurar propriedades e relacionamentos, levando-se em conta a localização espacial do fenômeno em estudo de maneira explícita (Câmara et al., 2009).

A análise de rede especializou-se em "desenhar" as redes de modo a melhor comunicar centralidades ou relacionamentos entre seus elementos (Brandes, Kenis, \& Raab, 2006; Fruchterman \& Reingold, 1991; Kamada \& Kawai, 1989), geralmente em duas ou três dimensões. Essas redes "espacialmente representadas" tornam-se "georreferenciadas", e todo o aparato analítico espacial torna-se apto. Zupic e Čater (2015) destacam que a utilização de mapas de calor construídos a partir da rede de associação entre elementos pode agregar valor a sua interpretação, e Rocha, Ponchio e Francisco (2015) utilizaram superfícies de intermediação para destacar colaboração entre países na produção científica de lealdade do consumidor e programas de fidelidade.

0 Gráfico 7, construída a partir do uso dos softwares ArcGIS ArcMap 10.2.1 e suas extensões Spatial Analyst e 3D Analyst (ESRI, 2016) apresenta a TIN desenvolvida a partir da centralidade de intermediação, para todo o acervo da RAE. Notam-se, no pico da superfície topográfica construída, as seis palavras-chave de maior intermediação da publicação. 
Gráfico 6. Componente principal da rede de associações entre as palavras-chave mais frequentes do periódico RAE de 1961 a 2016, global e por períodos de 14 anos
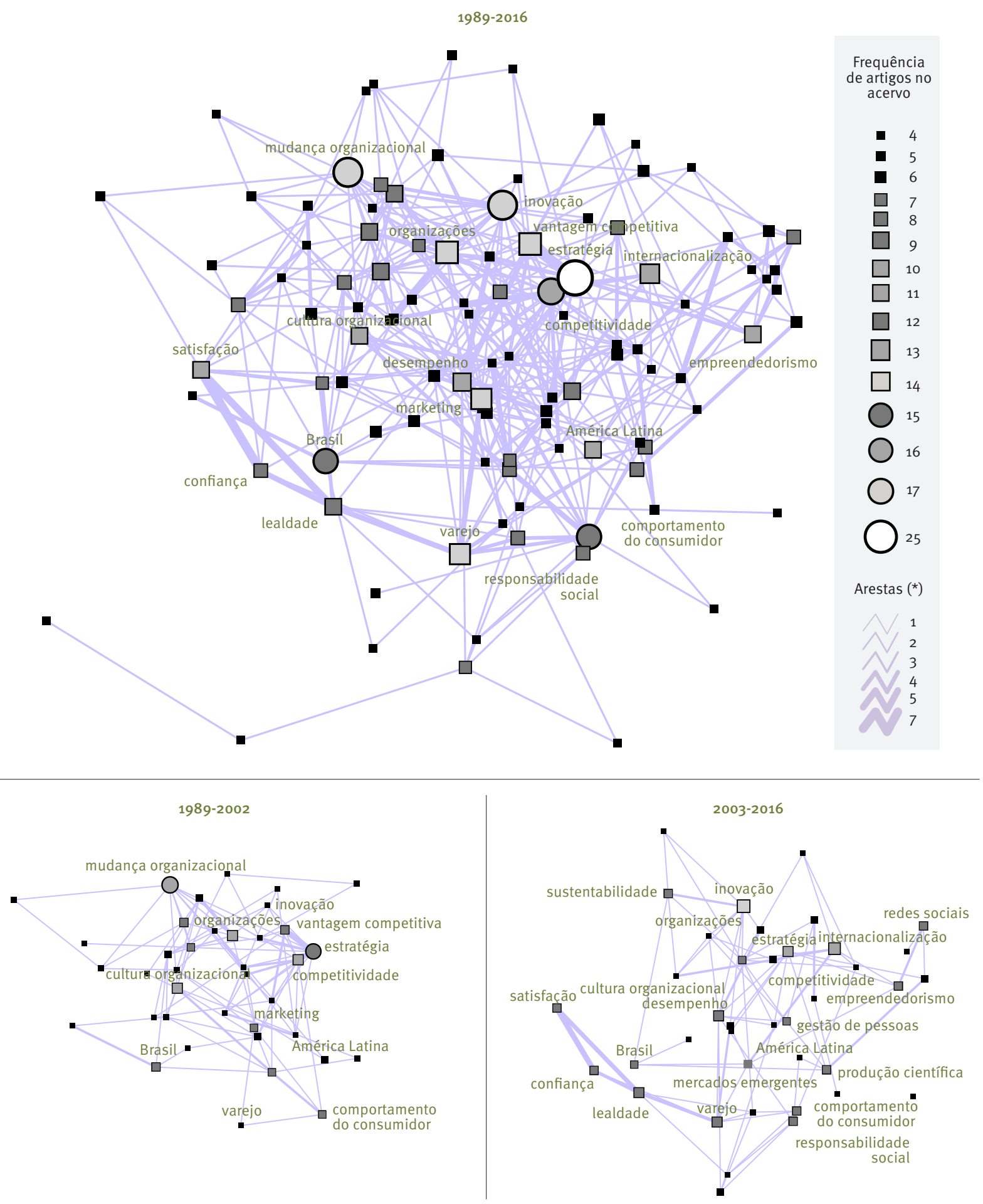

Nota: (a) A intensidade do traço da aresta é proporcional ao número de artigos em que as duas palavras-chave da aresta aparecem em conjunto.

Não há artigos com palavras-chave publicados até 1988. 
Tabela 5. Frequência, centralidade de grau e de intermediação das principais palavras-chave no periódico RAE até o final do ano de 2016, total e por períodos de 14 anos

\begin{tabular}{|c|c|c|c|c|c|c|c|c|c|}
\hline \multirow{2}{*}{ Palavra-chave } & \multirow{2}{*}{ Freq. } & \multirow{2}{*}{ Grau } & \multirow{2}{*}{ Intermed. } & \multicolumn{3}{|c|}{ 1989-2002 } & \multicolumn{3}{|c|}{$2003-2016$} \\
\hline & & & & Freq. & Grau & Intermed. & Freq. & Grau & Intermed. \\
\hline estratégia & 25 & 106 & $273.895,2$ & 15 & 66 & $50.655,2$ & 10 & 40 & $65.671,0$ \\
\hline mudança organizacional & 17 & 69 & $142.159,4$ & 16 & 65 & $61.518,4$ & 1 & 4 & 0 \\
\hline inovação & 17 & 68 & $120.829,1$ & 4 & 15 & $5.032,4$ & 13 & 53 & $70.935,7$ \\
\hline vantagem competitiva & 14 & 63 & $68.310,3$ & 8 & 39 & $10.312,1$ & 6 & 24 & $17.245,7$ \\
\hline Brasil & 15 & 58 & $178.056,9$ & 8 & 30 & $15.237,7$ & 7 & 28 & $40.079,7$ \\
\hline organizações & 14 & 54 & $77 \cdot 348,3$ & 10 & 38 & $22.176,5$ & 4 & 16 & $30.818,8$ \\
\hline marketing & 13 & 52 & $69.581,8$ & 7 & 28 & $17 \cdot 320,5$ & 6 & 24 & $20.113,7$ \\
\hline varejo & 13 & 52 & $52.991,0$ & 4 & 16 & $5.464,2$ & 9 & 36 & $56.745,5$ \\
\hline cultura organizacional & 10 & 41 & $61.230,5$ & 10 & 41 & $41.287,6$ & & & \\
\hline empreendedorismo & 10 & 40 & $53.030,8$ & 2 & 8 & $2.892,0$ & 8 & 32 & $34.236,7$ \\
\hline América Latina & 10 & 37 & $55 \cdot 917,5$ & 6 & 21 & $11.053,4$ & 4 & 16 & $10.582,4$ \\
\hline gestão de pessoas & 9 & 37 & $49.848,6$ & 2 & 8 & $2.733,1$ & 7 & 29 & $33.905,4$ \\
\hline teoria das organizações & 8 & 37 & $51.319,9$ & 5 & 24 & $19 \cdot 728,7$ & 3 & 13 & $9.050,4$ \\
\hline lealdade & 9 & 36 & $21.826,7$ & & & & 9 & 36 & $16.581,7$ \\
\hline globalização & 6 & 34 & $30.504,0$ & 6 & 34 & $31.137,3$ & & & \\
\hline marketing de relacionamento & 7 & 33 & $28.907,5$ & 4 & 21 & $8.087,7$ & 3 & 12 & $1.281,4$ \\
\hline motivação & 6 & 33 & $28.463,8$ & 4 & 25 & $13.488,0$ & 2 & 8 & $3.597,9$ \\
\hline internet & 8 & 32 & $71.858,1$ & 3 & 12 & $6.078,3$ & 5 & 20 & $37.762,2$ \\
\hline produção científica & 8 & 32 & $59.884,8$ & & & & 8 & 32 & $38.525,0$ \\
\hline produtividade & 8 & 32 & $54 \cdot 155,6$ & 6 & 24 & $17.746,9$ & 2 & 8 & $2.501,1$ \\
\hline redes sociais & 8 & 32 & $25.225,7$ & & & & 8 & 32 & $16.017,6$ \\
\hline $\begin{array}{l}\text { responsabilidade social } \\
\text { corporativa }\end{array}$ & 8 & 32 & $44.630,2$ & & & & 8 & 32 & $28.976,5$ \\
\hline trabalho & 8 & 32 & $51.725,6$ & 5 & 20 & $9.193,0$ & 3 & 12 & $9 \cdot 381,7$ \\
\hline estudos organizacionais & 8 & 31 & $41.265,1$ & 2 & 7 & $2.172,0$ & 6 & 24 & $28.313,4$ \\
\hline cultura & 8 & 30 & $52.677,4$ & 7 & 26 & $21.519,2$ & 1 & 4 & 0 \\
\hline administração pública & 6 & 29 & $27.416,2$ & 4 & 21 & $10.787,0$ & 2 & 8 & $2.185,0$ \\
\hline serviços & 6 & 29 & $31.618,3$ & 4 & 21 & $7.879,2$ & 2 & 8 & $4.888,5$ \\
\hline governança corporativa & 7 & 28 & $73.559,8$ & 1 & 4 & 0 & 6 & 24 & $45 \cdot 525,9$ \\
\hline mercados emergentes & 7 & 28 & $61.110,9$ & & & & 7 & 28 & $36.399,0$ \\
\hline responsabilidade social & 7 & 28 & $38.282,2$ & 4 & 17 & $9.152,9$ & 3 & 11 & $12.514,9$ \\
\hline
\end{tabular}



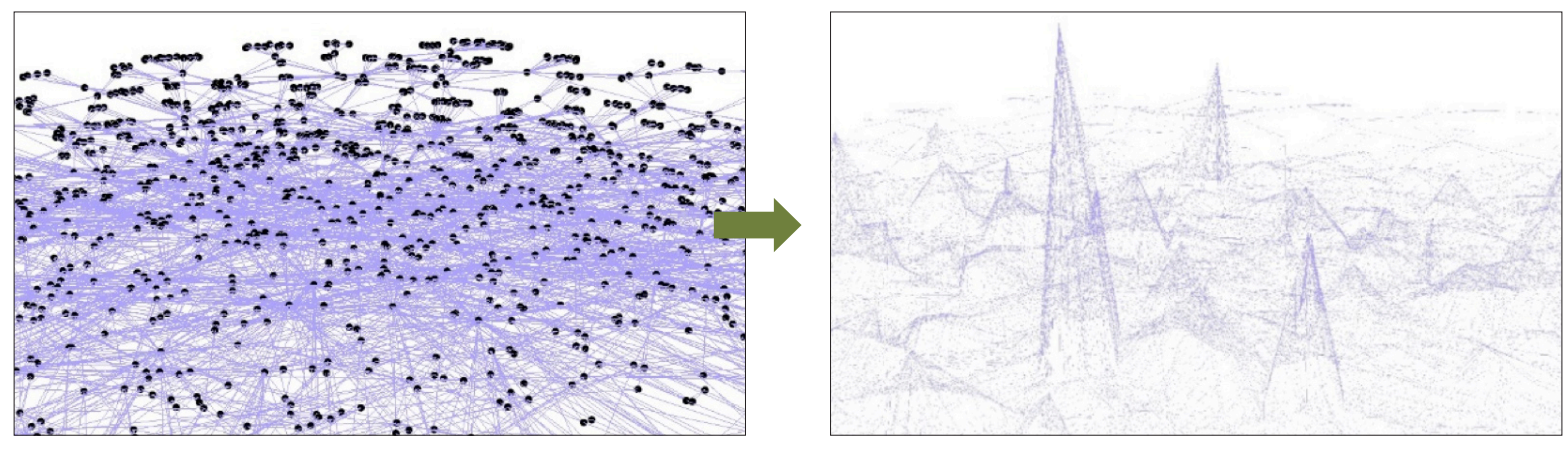

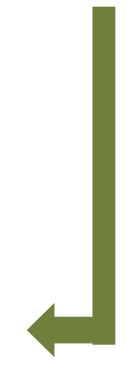

TIN - Rede de triângulos irregulares Intermediação (elevação)

$\square 243482.381-273895.156$ 213029.500- 243462361 — $182590.771-213029566$ $152163.976-182598.771$ — $121731.181-152163.978$ - $91298.385-121731.181$ 60865.59-91298.385 30432.795-60865.59 - 0.30432 .795

\section{Editoriais - Palavras simples mais frequentes no conteúdo (corpo) do texto}

Nem todas as edições da RAE publicaram um documento específico como editorial, especialmente as mais antigas. Ainda assim, com o procedimento de integração do conteúdo texto disponível nos 217 editoriais (coletados nos arquivos PDFs digitalizados pela Biblioteca Digital FGV), foram identificados arquivos que traziam certa mensagem padrão (sugerindo a ausência do editorial), bem como alguns com conteúdo em branco. Dessa forma, foi possível manter um número de 117 arquivos que tiveram seus conteúdos extraídos, integralizados e analisados com base na primeira
Lei de Zipf (Piantadosi, 2014; Zipf, 1949), com a identificação das 25 palavras simples com maior ocorrência, e informadas na Tabela 6, além de ser elaborada uma "nuvem" dessas palavras, disponibilizada na Figura 5. A utilização da primeira Lei de Zipf, que em seu enunciado descreve a relação $r . f=c$, em que, para um dado conteúdo de texto, a ordem de série ou rank (r) de uma palavra multiplicada pela sua frequência de ocorrência (f) é uma constante (c), permite verificar "recortes" do determinado corpo/campo de conhecimento que se estuda por intermédio do comportamento da ocorrência de termos mais frequentes (Chueke \& Amatucci, 2015), propondo que as palavras mais usadas em um documento indiquem o assunto associado ao documento. 
Figura 5. Nuvem (word cloud) de palavras simples mais frequentes no conteúdo completo dos editoriais da RAE

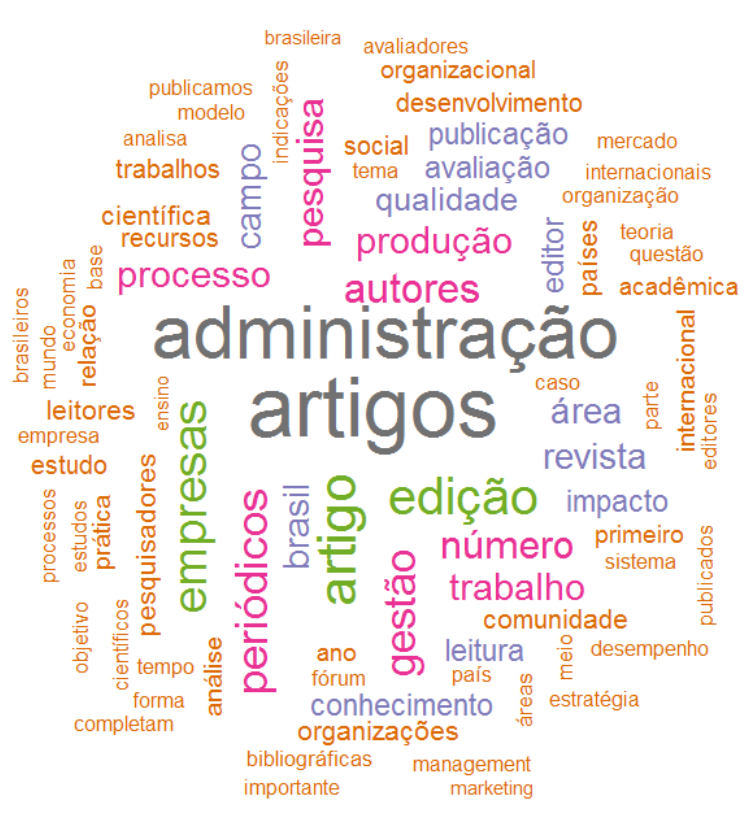

Tabela 6. Lista ordenada das 25 palavras simples com a ocorrência mais frequente no conteúdo dos editoriais da $R A E$, no período entre 1961 e 2016

\begin{tabular}{|c|c|c|c|}
\hline Palavra simples & Freq. (f) & Rank (r) & Constante (f. $r=c$ ) \\
\hline artigos & 382 & 12 & 4584 \\
\hline administração & 335 & 14 & 4690 \\
\hline edição & 222 & 21 & 4662 \\
\hline empresas & 200 & 22 & 4400 \\
\hline periódicos & 179 & 24 & 4296 \\
\hline autores & 160 & 30 & 4800 \\
\hline número & 156 & 32 & 4992 \\
\hline produção & 149 & 35 & 5215 \\
\hline pesquisa & 148 & 36 & 5328 \\
\hline trabalho & 148 & 37 & 5476 \\
\hline área & 137 & 42 & 5754 \\
\hline campo & 125 & 44 & 5500 \\
\hline qualidade & 114 & 49 & 5586 \\
\hline editor & 106 & 52 & 5512 \\
\hline leitura & 103 & 53 & 5459 \\
\hline avaliação & 102 & 55 & 5610 \\
\hline conhecimento & 101 & 56 & 5656 \\
\hline impacto & 97 & 59 & 5723 \\
\hline publicação & 96 & 60 & 5760 \\
\hline comunidade & 95 & 61 & 5795 \\
\hline
\end{tabular}




\section{Pensatas - Palavras mais frequentes no conteúdo (corpo) do texto}

A primeira publicação de documento do tipo pensata no periódico RAE ocorreu no ano de 2001, volume 41, número 3, intitulada “Orquestras sinfônicas: Uma metáfora revisitada”, de autoria do professor Carlos Osmar Bertero (Bertero, 2001). Do total de 62 pensatas publicadas entre 2001 e 2016 (volume 56, número 5), uma foi redigida no idioma francês, duas no idioma espanhol e outras nove no idioma inglês - as 50 restantes, no idioma português. A partir da extração e análise de conteúdo desses documentos na língua portuguesa, foram identificadas as palavras simples com maior ocorrência e elaborada uma "nuvem" dessas palavras (Figura 6).

Figura 6. Nuvem (word cloud) de palavras simples mais frequentes no conteúdo completo das pensatas publicadas em língua portuguesa na RAE, no período entre 2001 e 2016

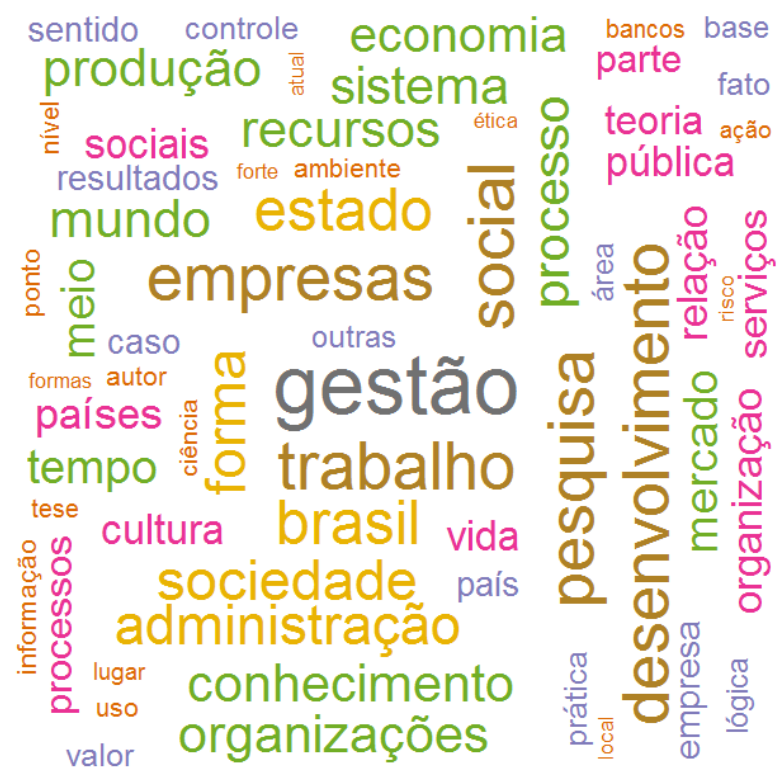

\section{Resenhas - Palavras mais frequentes no conteúdo (corpo) do texto}

O primeiro documento do tipo resenha publicado no periódico RAE ocorreu no volume 1, número 1 (maio-agosto/1961), de autoria de Vergil D. Reed, da Michigan State University (Reed, 1961), a qual relatava sobre o livro Management in the industrial world: An international analysis, dos autores Frederick Harbison e Charles A. Myers, com 413 páginas, e da editora McGraw-Hill Book Company. De 1961 até 2016, um total de 680 artigos foi identificado como resenhas, e em cinco deles não foi possível realizar a extração do conteúdo, devido à ausência do texto no documento ou de sua digitalização trazer o conteúdo texto gravado como imagem. Assim, com a extração e análise do conteúdo de texto completo de 675 resenhas, foi possível identificar a lista das palavras simples mais frequentes nesses documentos, e então foi criada uma "nuvem" com essa identificação (Figura 7).

A Figura 7 informa as palavras simples mais frequentes em todo o conteúdo dos textos de 675 resenhas publicadas no periódico RAE. Foram identificadas, nas duas primeiras colocações, as palavras: “livro”, com frequência de 3.347 vezes, e “autor”, com frequência de 2.573 ocorrências. 
Figura 7. Nuvem (word cloud) de palavras simples mais frequentes no conteúdo completo das resenhas publicadas na $R A E$, no período entre 1961 e 2016

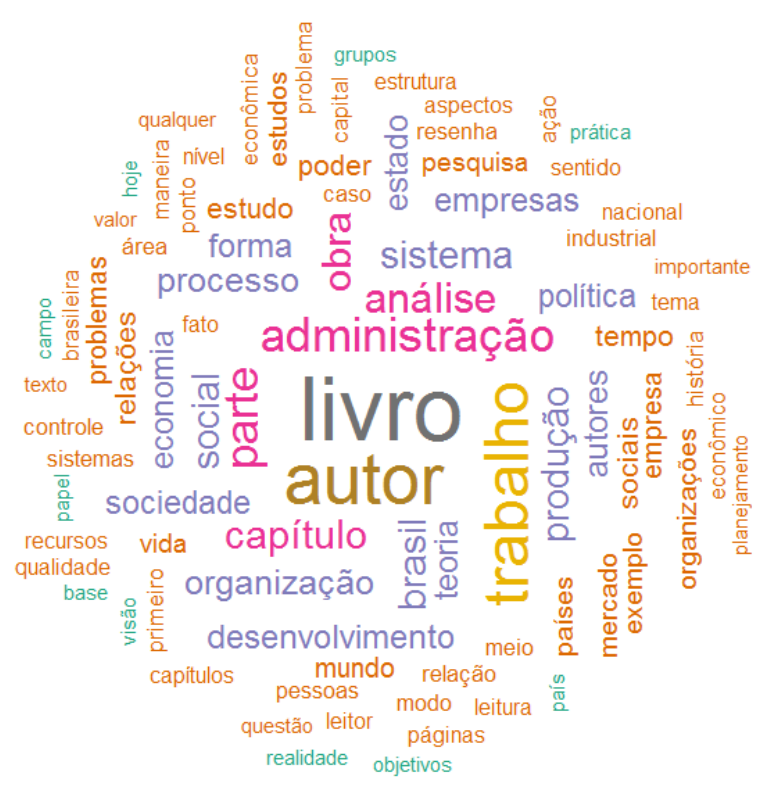

\section{CONCLUSÃO}

Este artigo explorou e analisou o acervo de documentos do periódico RAE, de 1961 a 2016, composto por artigos (incluindo fórum), editoriais, pensatas e resenhas, pelo acesso aos documentos disponibilizados via internet no repositório eletrônico de periódicos e revistas da Biblioteca Digital da FGV EAESP, o qual segue o protocolo aberto OAI-PMH de interoperabilidade entre repositórios digitais.

Foi mapeada e compreendida detalhadamente a trajetória de existência ininterrupta do periódico, pela utilização nos documentos de até quatro técnicas de análise: bibliometria, text mining, análise de rede social e geoanálise. A pesquisa identificou que 0 autor mais prolífico contribuiu com 28 artigos para o periódico entre 1964 e 1987, além de as publicações de artigos no periódico ocorrerem amplamente pela autoria única ou de duplas entre 1961 e 2002, gerando, no período, cerca de $95 \%$ das publicações dessa forma.

No último período avaliado por este estudo (2013-2016), ficou identificado que $88,4 \%$ dos artigos publicados no periódico foram redigidos por dois, três ou quatro autores, demonstrando claramente que o quesito colaboração é cada vez mais valorizado pelo periódico. A existência de componentes com 141, 34 e 23 autores interligados na rede de coautorias, totalizando $17,6 \%$ dos autores em colaboração e 12,6\% do total de autores, indica uma alta densidade de colaboração, relativa à topologia típica de análises de coautorias em periódicos científicos de Administração, construída ao longo das mais de cinco décadas de produção do periódico.

Em todo o acervo da RAE analisado no período de 1961 a 2016, três palavras simples foram identificadas nas listas de 25 principais ocorrências de palavras em diferentes blocos dos documentos avaliados (artigos e fórum - títulos, palavraschave e resumos; editoriais, pensatas, e resenhas - conteúdo completo): “administração", "empresas” e "trabalho". Dessa mesma forma, outras três palavras simples foram identificadas em cinco dessas listas: "Brasil" (exceto nos resumos de artigos), "gestão" (exceto nas resenhas) e "pesquisa" (exceto nas resenhas). Todas as quatro palavras simples ("análise", "desenvolvimento", “mercado" e "organizações”) estão nas listas das 25 palavras de maior ocorrência nos títulos e nos resumos dos artigos (inclui fórum) que foram publicados no periódico.

A palavra "administração" - identificada em todas as seis listas de ocorrência das 25 palavras mais frequentes - ficou classificada na: segunda posição no conteúdo total dos editoriais, quarta posição no conteúdo total das resenhas, quinta posição nos títulos dos artigos, sexta posição nas palavras-chave dos artigos, $11^{-a}$ posição no conteúdo total das pensatas e $24^{-a}$ posição nos resumos dos artigos.

Por sua vez, a palavra "empresas" - também identificada em todas as seis listas de ocorrência das 25 palavras mais 
frequentes - ficou classificada na: primeira posição nos resumos dos artigos, segunda posição nos títulos dos artigos, quarta posição no conteúdo total das pensatas, quinta posição no conteúdo total dos editoriais, nona posição nas palavras-chave dos artigos e 15 a posição no conteúdo total das resenhas, do acervo de documentos publicados no periódico entre 1961 e 2016.

Em síntese, a rede de palavras-chave destacou, entre os conceitos de alta frequência, grau e intermediação discutidos no acervo de artigos (incluindo fórum), “estratégia”, "inovação” e "comportamento do consumidor", termos que se mantiveram centrais na construção da história da $R A E$ e, por conseguinte, da produção científica em Administração no Brasil, e as palavras "empresa(s)", "administração" e "trabalho" foram largamente utilizadas nos resumos de artigos, editoriais, resenhas, pensatas e títulos.

\section{LIMITAÇÕES E ESTUDOS FUTUROS}

Este estudo contemplou somente a análise de documentos publicados na $R A E$ redigidos na língua portuguesa, sem incluir aqueles com redação em inglês, espanhol ou francês.

Ao optar pela escolha da base de dados dos documentos da $R A E$ disponibilizada via repositório eletrônico de periódicos e revistas da Biblioteca Digital da FGV EAESP (FGV, 2017b), em detrimento das outras duas opções - bases de dados da RAE Editora (RAE, 2017a) ou mesmo aquela do indexador SciELO (SciELO Brasil, 2017b), não foram poupados esforços no refinamento dos dados coletados, bem como em suas análises. Mesmo assim, os autores reiteram que a replicação do trabalho com a utilização de outras opções de bases de dados poderá apontar diferenças, muito provavelmente em virtude do procedimento adotado na conversão do acervo originalmente produzido (impresso em papel) para o formato eletrônico (digital), bem como o quão criteriosos foram os procedimentos adotados nessa conversão pelas equipes de gerenciamento de cada uma dessas bases de dados.

Este artigo não procurou identificar redes de citação existentes nas listas de referências de todos os artigos publicados no periódico $R A E$, limitando-se a identificar as redes entre os autores da seção Artigo (inclui fórum) das edições de 1961 até o ano de 2016 e as redes de palavras-chave (estas, do ano de 1989, volume 25 , número 4, até 2016, volume 56, número 6). Além disso, devido a os nomes das Instituições de Ensino Superior (IES) onde cada autor possui vínculo acadêmico não estarem disponíveis para coleta automatizada, não foi possível contemplar neste estudo qualquer análise que envolvesse os nomes de tais instituições.
Pela análise do acervo integral da $R A E$ de 1961 a 2016, percebe-se que, a partir do ano de 2004, os artigos científicos publicados no periódico ganharam a participação de mais coautores - aqui há claramente uma oportunidade para estudos futuros, com investigação mais ampla das temáticas abordadas nos artigos, na composição da rede de autoria formada por esses autores, bem como das conexões formadas entre as instituições acadêmicas a que esses autores estão vinculados.

A oportunidade de realização deste estudo não se esgota em seus achados analíticos nem na coerência que a evolução do pensamento científico em Administração apresentou nesses mais de 50 anos, mas, sim, expande a possibilidade de vislumbrarmos as transformações potenciais para o futuro. E que venham mais décadas de publicação.

\section{REFERÊNCIAS}

Abbasi, A., Hossain, L., \& Leydesdorff, L. (2012). Betweenness cen trality as a driver of preferential attachment in the evolution of research collaboration networks. Journal of Informetrics, 6(3), 403-412. doi:10.1016/j.joi.2012.01.002

Albuquerque, J. P. de. (2012). Flexibilidade e modelagem de processos de negócio: Uma relação multidimensional. RAE-Revista de Administração de Empresas, 52(3), 313-329. doi:10.1590/Soo3475902012000300004

Amemiya, T. (2009). Thirty-five years of journal of econometrics. Journal ofEconometrics, 148(2), 179-185. doi:10.1016/j.jeconom.2008.10.011

Banker, R. D., \& Kauffman, R. J. (2004). The evolution of research on information systems: A fiftieth-year survey of the literature in management science. Management Science, 50(3), 281-298. doi:10.1287/ mnsc.1040.0206

Bertero, C. O. (2001). Pensata - Orquestras sinfônicas: Uma metáfora revisitada. RAE-Revista de Administração de Empresas, 41(3), 84-88. doi:10.1590/So034-75902001000300011

Bertero, C. O. (2006). A RAE nos seus 45 anos. RAE-Revista de Administração de Empresas, 46(2), 114-117. doi:10.1590/So03475902006000200008

Bertero, C. O. (2011). Meio século de RAE. RAE-Revista de Administração de Empresas, 51(3), 224-226. doi:10.1590/Soo3475902011000300002

Brandes, U., Kenis, P., \& Raab, J. (2006). Explanation through network visualization. Methodology, 2(1), 16-23. doi:10.1027/1614-1881.2.1.16

Câmara, G., Vinhas, L., Davis, C., Fonseca, F., \& Carneiro, T. (2009). Geographical information engineering in the 21st century. In G. Navratil (Ed.) Research trends in geographic information science (pp. 203218). Berlin, Germany: Springer Berlin Heidelberg. doi:10.1007/9783-540-88244-2_14

Coordenação de Aperfeiçoamento de Pessoal de Nível Superior. (2017). Plataforma Sucupira - Periódicos Qualis. Recuperado de https:// sucupira.capes.gov.br/sucupira/ 
Chueke, G. V., \& Amatucci, M. (2015). O que é bibliometria? Uma introdução ao fórum. InternexT - Revista Eletrônica de Negócios Internacionais da ESPM, 10(2), 1-5. doi:10.18568/1980-4865.1021-5

Comassetto, B. H., Solalinde, G. P., Souza, J. V. R. de, Trevisan, M., Abdala, P. R. Z., \& Rossi, C. A. V. (2013). Nostalgia, anticonsumo simbólico e bem-estar: A agricultura urbana. RAE-Revista de Administração de Empresas, 53(4), 364-375. doi:10.1590/So034-75902013000400004

Diniz, E. H. (2010). Editorial. RAE-Revista de Administração de Empresas, 50(2), 4. doi:10.1590/S0034-75902010000200001

Diniz, E. H. (2014). Internacionalização da RAE-Revista de Administração de Empresas. Recuperado de http://humanas.blog.scielo. org/blog/2014/12/17/internacionalizacao-da-RAE-revista-de-administracao-de-empresas/

Diniz, E. H. (2015). Editorial. Internacionalização da RAE: 0 caminho trilhado entre 2009 e 2015. RAE-Revista de Administração de Empresas, 55(6), 611. doi:10.1590/So034-759020150601

Diniz, E. H. (2016). Editorial. Sete anos depois, a despedida. RAE-Revista de Administração de Empresas, 56(1), 7. doi:10.1590/So034759020160101

Diniz, E. H. (2017). Os periódicos brasileiros da área de administração no contexto da internacionalização da produção científica. $R A E-R e-$ vista de Administração de Empresas, 57(4), 357-364. doi: 10.1590/ So034-759020170406

Dolamic, L., \& Savoy, J. (2010). When stopword lists make the difference. Journal of the American Society for Information Science and Technology, 61(1), 200-203. doi:10.1002/asi.21186

Environmental Systems Research Institute. (2016). ArcGIS Desktop: Release 10.5. Redlands, USA: ESRI. Recuperado de http://desktop. arcgis.com/en/arcmap

Feinerer, I., Hornik, K., \& Meyer, D. (2008). Text mining infrastructure in R. Journal of Statistical Software, 25(5), 1-54. doi:10.18637/jss.v025. io5

Fleet, D. D. Van, \& Bedeian, A. G. (2016). The Journal of Management's first 40 years. Journal of Management, 42(2), 349-356. doi:10.1177/0149206315609403

Floriani, L. De. (1987). Data structures for encoding triangulated irregular networks. Advances in Engineering Software, 9(3), 122-128. doi: 10.1016/0141-1195(87)90001-5

Francisco, E. R. (2011). RAE-Eletrônica: Exploração do acervo à luz da bibliometria, geoanálise e redes sociais. RAE-Revista de Administração de Empresas, 51(3), 280-306. doi:10.1590/So03475902011000300008

Fruchterman, T. M. J., \& Reingold, E. M. (1991). Graph drawing by force-directed placement. Software: Practice and Experience, 21(11), 1129-1164. doi:10.1002/spe.4380211102

Fundação Getulio Vargas. (1961). Carta de apresentação - Revista de Administração de Empresas. FGV - Escola de Administração de Empresas de São Paulo. RAE-Revista de Administração de Empresas, 1(1), 11-12. doi:10.1590/So034-75901961000100001

Fundação Getulio Vargas. (2017a). Biblioteca digital FGV - OAl 2.0 Request Results. Recuperado de http://bibliotecadigital.fgv.br/ojs/index.php/RAE/oai/?verb=ListSets
Fundação Getulio Vargas. (2017b). Repositório FGV de periódicos e revistas. Biblioteca digital da RAE - Revista de Administração de Empresas. Fundação Getulio Vargas - Escola de Administração de Empresas de São Paulo. Recuperado de http://bibliotecadigital.fgv. $\mathrm{br} / \mathrm{ojs} /$ index.php/RAE

Goldenstein, G. T. (1991). Carta ao leitor - 30 aniversário da RAE. RAE-Revista de Administração de Empresas, 31(2). doi:10.1590/ So034-75901991000200001

Guimarães, A., Missel, D., \& Zunder, O. (1965). Treinamento industrial em São Paulo. RAE-Revista de Administração de Empresas, 5(16), 21 58. doi:10.1590/So034-75901965000300001

Hanneman, R. A., \& Riddle, M. (2005). Introduction to social network methods. Riverside, USA: University of California. Recuperado de http://faculty.ucr.edu/ hanneman/nettext/Introduction_to_Social_ Network_Methods.pdf

Hashimi, H., Hafez, A., \& Mathkou, H. (2015). Selection criteria for text mining approaches. Computers in Human Behavior, 51, 729-733. doi:10.1016/j.chb.2014.10.062

Hood, W. W., \& Wilson, C. S. (2001). The literature of bibliometrics, scientometrics, and informetrics. Scientometrics, 52(2), 291-314. doi:10.1023/A:1017919924342

Huang, Y. (1989). Triangular irregular network generation and topographical modeling. Computers in Industry, 12(3), 203-213. doi:10.1016/0166-3615(89)90067-5

Journal Citation Reports. (2017). Thomson Reuters (Clarivate Analytics). Recuperado de http://wokinfo.com/products_tools/analytical/jcr/

Kamada, T., \& Kawai, S. (1989). An algorithm for drawing general undirected graphs. Information Processing Letters, 31(1), 7-15. doi:10.1016/0020-0190(89)90102-6

Kayser, V., \& Blind, K. (2017). Extending the knowledge base of foresight: The contribution of text mining. Technological Forecasting and Social Change, 116, 208-215. doi:10.1016/j.techfore.2016.10.017

Machline, C. (1961). Inflação e lote econômico de compra. RAE-Revista de Administração de Empresas, 1(1), 17-33. doi:10.1590/Soo3475901961000100002

Martes, A. C. B., Bulgacov, S., Nascimento, M. R. do, Gonçalves, S. A., \& Augusto, P. M. (2006). Redes sociais e interorganizacionais. RAE-Re vista de Administração de Empresas, 46(3), 10-15. doi:10.1590/ So034-75902006000300002

Medeiros, C. (2016). Ranking SCIELO - Top 10 revistas com mais acessos (2015-2016). Recuperado de http://www.blogs.ea2.unicamp.br/ cienciaemrevista/2016/10/19/ranking-scielo/

Mingers, J., \& Leydesdorff, L. (2015). A review of theory and practice in scientometrics. European Journal of Operational Research, 246, 1-19. doi:10.1016/j.ejor.2015.04.002

Minitab. (2017). Minitab 17 Statistical Software. Recuperado de http:// support.minitab.com/en-us/minitab/17

Motta, I. de S., \& Hopp, J. C. (1961). Fundo de comércio: Sua conceituação legal e avaliação contábil. RAE-Revista de Administração de Empresas, 1(1), 57-64. doi:10.1590/So034-75901961000100004

Open Archives Initiative. (2017). The Open Archives Initiative Protocol for Metadata Harvesting. Recuperado de https://www.openarchives. org/OAl/openarchivesprotocol.html 
Perl. (2017). About Perl: What is Perl? Features and history. Recuperado de https://www.perl.org/about.html

Piantadosi, S. T. (2014). Zipf's word frequency law in natural language: A critical review and future directions. Psychonomic Bulletin \& Review, 21(5), 1112-1130. doi:10.3758/s13423-014-0585-6

R Core Team. (2017). R: A language and environment for statistical computing. Vienna, Austria: R Foundation for Statistical Computing. Recuperado de https://www.r-project.org

Reed, V. D. (1961). Management in the industrial world: An international analysis. RAE-Revista de Administração de Empresas, 1(1), 141-143. doi:10.1590/So034-75901961000100010

Revista de Administração de Empresas. (2016). RAE é uma das revistas mais acessadas no portal SciELO. Recuperado de http://RAE.fgv.br/ node/52799

Revista de Administração de Empresas. (2017a). RAE-Revista de Administração de Empresas. Fundação Getulio Vargas - Escola de Administração de Empresas de São Paulo. Recuperado de http://RAE.fgv.br

Revista de Administração de Empresas. (2017b). RAE-Revista de Administração de Empresas. Quem somos. Fundação Getulio Vargas - Escola de Administração de Empresas de São Paulo. Recuperado de http://RAE.fgv.br/RAE-pub

Ribeiro, H. C. M. (2014a). Doze anos de estudo da Revista de Administração Pública à luz da bibliometria e da rede social. Revista Ciências Administrativas, 20(1), 137-167. doi:10.5020/2318-0722.2014. v2on1p167

Ribeiro, H. C. M. (2014b). Produção acadêmica do periódico Internext de 2006 a 2013. InternexT - Revista Eletrônica de Negócios Internacionais da ESPM, 9(3), 95-118. Recuperado de http://www.spell.org. $\mathrm{br} /$ documentos/ver/33707

Ribeiro, H. C. M. (2015). Quinze anos de estudo da Revista de Administração Contemporânea sob a ótica da bibliometria e da rede social. Perspectivas em Gestão \& Conhecimento, 5(Número Especial), 86-108. Recuperado de http://periodicos.ufpb.br/index.php/pgc/ article/view/22918

Ribeiro, H. C. M., \& Corrêa, R. (2014). 10 anos de pesquisa da Revista Brasileira de Inovação sob a ótica da bibliometria e da rede social. Administração: Ensino e Pesquisa (RAEP), 15(4), 729-767. doi:10.13058/RAEp.2014.v15n4.8

Ribeiro, H. C. M., Corrêa, R., Costa, B. K., \& Fischmann, A. A. (2016). 35 anos de publicações acadêmicas da Revista de Administração da USP. Revista Ambiente Contábil, 8(1), 294-322. Recuperado de http://www.periodicos.ufrn.br/ambiente
Ribeiro, H. C. M., \& Costa, B. K. (2013). Brazilian administration review: Uma análise do perfil da produção acadêmica científica no período de 2004 a 2012 sob a ótica da rede social e da bibliometria. Revista de Ciências da Administração, 15(37), 65-81. doi:10.5007/2175 8077.2013v15n37p65

Rocha, V. M., Ponchio, M. C., \& Francisco, E. de R. (2015). Lealdade do consumidor e programas de fidelidade: Uma análise topográfica do campo de conhecimento à luz da bibliometria, da estatística espacial e das redes sociais. Revista de Ciências da Administração, 17(41), 9-20. doi:10.5007/2175-8077.2015V17n41po9

Rodrigues, S. B., Barbosa, F. V., Luz, T. R. da, \& Kilimnik, Z. M. (1985). Microeletrônica e organização do trabalho no setor de serviços. RAE-Revista de Administração de Empresas, 25(4), 5-19. doi:10.1590/ So034-75901985000400001

Rosa, A. R., \& Santos, A. L. Dos. (2012). Uma década de GVexecutivo. GV-executivo, 11(2), 76-79. doi:10.1266o/gvexec.v11n2.2012.22466

Scientific Electronic Library Online. (2017). SciELO Analytics - Frequent questions (Accesses). Recuperado de http://analytics.scielo.org/w/faq

Scientific Electronic Library Online Brasil. (2017a). Acervo completo da Revista de Administração de Empresas (RAE). Recuperado de http:// www.scielo.br/scielo.php?script $=$ sci_issues $\&$ pid $=0034-7590 \& \mathrm{l}-$ $\mathrm{ng}=\mathrm{en} \& \mathrm{nrm}=\mathrm{iso}$

Scientific Electronic Library Online Brasil. (2017b). Revista de Administração de Empresas (RAE). Recuperado de http://www.scielo.br/RAE

Scimago Journal \& Country Rank. (2017). SJR. Recuperado de http:// www.scimagojr.com/journalsearch.php

The Comprehensive Perl Archive Network. (2017). CPAN. Recuperado de http://www.cpan.org

Tigre, P. B., Rovere, R. L. La, Teixeira, F. L. C., López, A., Ramos, D., Bercovich, N., ... Rodrigues, R. F. (2011). Knowledge cities: A taxonomy for analyzing software and information service clusters. RAE-Revista de Administração de Empresas, 51(1), 15-26. doi:10.1590/So03475902011000100003

Zheng, X., Le, Y., Chan, A. P. C., Hu, Y., \& Li, Y. (2016). Review of the application of social network analysis (SNA) in construction project management research. International Journal of Project Management, 34(7), 1214-1225. doi:10.1016/j.ijproman.2016.06.005

Zipf, G. K. (1949). Human behavior and the principle of least effort. Cambridge, USA: Addison-Wesley.

Zupic, I., \& Čater, T. (2015). Bibliometric methods in management and organization. Organizational Research Methods, 18(3), 429-472. doi:10.1177/1094428114562629 